\title{
Reflections on the history of pre-mRNA processing and highlights of current knowledge: A unified picture
}

\author{
JAMES E. DARNELL, JR. ${ }^{1}$ \\ Laboratory of Molecular Cell Biology, Rockefeller University, New York, New York 10065, USA
}

\begin{abstract}
Several strong conclusions emerge concerning pre-mRNA processing from both old and newer experiments. The RNAPII complex is involved with pre-mRNA processing through binding of processing proteins to the CTD (carboxyl terminal domain) of the largest RNAPII subunit. These interactions are necessary for efficient processing, but whether factor binding to the CTD and delivery to splicing sites is obligatory or facilitatory is unsettled. Capping, addition of an $\mathrm{m}^{7} \mathrm{Gppp}$ residue (cap) to the initial transcribed residue of a pre-mRNA, occurs within seconds. Splicing of pre-mRNA by spliceosomes at particular sites is most likely committed during transcription by the binding of initiating processing factors and $\sim 50 \%$ of the time is completed in mammalian cells before completion of the primary transcript. This fact has led to an outpouring in the literature about "cotranscriptional splicing." However splicing requires several minutes for completion and can take longer. The RNAPII complex moves through very long introns and also through regions dense with alternating exons and introns at an average rate of $\sim 3 \mathrm{~kb}$ per min and is, therefore, not likely detained at each splice site for more than a few seconds, if at all. Cleavage of the primary transcript at the $3^{\prime}$ end and polyadenylation occurs within $30 \mathrm{sec}$ or less at recognized polyA sites, and the majority of newly polyadenylated pre-mRNA molecules are much larger than the average mRNA. Finally, it seems quite likely that the nascent RNA most often remains associated with the chromosomal locus being transcribed until processing is complete, possibly acquiring factors related to the transport of the new mRNA to the cytoplasm.
\end{abstract}

Keywords: pre-mRNA processing

\section{INTRODUCTION}

The molecular processes in the manufacture of mRNAs in eukaryotic cells are certainly among, if not the most, complicated events in all of cell biology and biochemistry. Not only is there an elaborate set of factors that instruct RNA polymerase II (RNAPII) to begin synthesis and then elongate the nascent RNA chain, but the correct processing of the primary RNA transcript (the pre-mRNA) and delivery of the mRNA to the cytoplasm seem equally, if not more, complex. The essence of experimental success in understanding the details of pre-mRNA synthesis and processing in the cell nucleus did and still does depend on the study of nascent RNA and associations of factors and the time, order, and specificity of their action on the pre-mRNA.

Experiments now 35-50 yr old arguably provide the best estimates of the actual elapsed times for some of these events, while an enormous cascade of newer experiments provides the most complete information about the mechanisms of delivery and actions of the large number of single processing proteins and complexes of proteins and RNAs, as well as the

\footnotetext{
${ }^{1}$ Corresponding author

E-mail darnell@rockefeller.edu

Article published online ahead of print. Article and publication date are at http://www.rnajournal.org/cgi/doi/10.1261/rna.038596.113.
}

nuclear location of pre-mRNA processing. Several recent papers examining nascent RNA have added considerable clarity to the questions of the timing, order, and cellular location of the final processing events and provide a strong stimulus for a consideration of the old results and interweaving with the new evidence. All this information, obtained with a variety of different techniques during the different eras, meshes well.

\section{A BRIEF HISTORY OF EUKARYOTIC RNA SYNTHESIS LEADING TO RECOGNITION OF POLYADENYLATION AND SPLICING OF MRNA}

RNA in eukaryotic cells was recognized very early by Jean Brachet, the Belgium biologist (Brachet 1941, 1955), as a legitimate entity for study in cell biology and not just another polysaccharide curiosity. Among the things that Brachet showed in Acetabularia was that the enucleated cell which contained the majority of basophilic staining material (RNA) could continue to incorporate labeled amino acids for several days (Brachet 1955). Of course, the chromosomes and DNA were thought by many before, and finally universally accepted after, the 1953 Watson-Crick structure to be the seat of genetic information.

However, it took another 6-7 yr for the three different major roles and species of RNA (including their sizes) to be 
recognized in bacteria. The two (major) ribosomal RNAs were established to be $\sim 1.5$ and $\sim 3.0 \mathrm{~kb}$ continuous polyribonucleoide chains, and these molecules were stable (Davern and Meselson 1960; Kurland 1960). Bacterial mRNA appeared to be an unstable minor fraction of the total RNA and ranged between 1 and $2 \mathrm{~kb}$. Therefore, a very short label time was required to reveal its existence (Brenner et al. 1961; Gros et al. 1961).

By the late 1950s, radioactively labeled ribonucleosides $\left({ }^{3} \mathrm{H}\right.$ and ${ }^{14} \mathrm{C}$ ) and ${ }^{32} \mathrm{PO}_{4}$ were widely available. RNA labeled with these isotopes in nucleated cells (animal and plant) was studied mainly by autoradiography and primitive methods of total RNA extraction (usually with alkaline solutions). Two central conclusions were frequently stated-first, the nucleus was where RNA synthesis was fastest (i.e., acquired label first) (Smellie 1955); and second, by (partially effective) pulse-chase experiments, particularly in the laboratory of Henry Harris (Harris 1959; Harris and LaCour 1963), nuclear RNA was deemed too unstable to be transferred (at least wholesale) to the cytoplasm.

When individual ribosomal RNAs were recognized to be stable and uniform in size in bacteria and in animal cells (Hall and Doty 1959), while mRNA in bacteria was unstable, it seemed time in the early 1960 s to try to understand nuclear RNA in eukaryotic cells and its possible relationship to protein synthesis known to occur mainly in the cytoplasm. Assuming that messenger RNA existed in eukaryotes, how did it get formed? The natural place to begin was to examine the newly formed, probably unstable nuclear RNA.

Klaus Scherrer and I at MIT and Bob Perry at Fox Chase Cancer Institute in Philadelphia began such experiments in 1961. We extracted from cultured mammalian cells the total cell RNA (with a hot phenol procedure) that had been labeled for a few minutes or more than a generation. This RNA was presumably intact because the procedure yielded whole infectious 7000-nt poliovirus RNA from infected cells. The size of the cellular RNA was determined and its base composition compared to that of the total DNA. These results were reported early in 1962, $50 \mathrm{yr}$ ago as this is written (Darnell 1962; Perry 1962; Scherrer and Darnell 1962).

Perforce, the challenge of finding eukaryotic mRNA when the vast majority of brief radioactive label incorporation was nuclear led to the field of eukaryotic RNA processing. The first experiments using sedimentation analysis revealed very large, variously sized nuclear RNAs, some over $20 \mathrm{~kb}$ long but much smaller functional cytoplasmic rRNAs. By 15-30 min dominant peaks at $45 \mathrm{~S}(\sim 14 \mathrm{~kb})$ and $32 \mathrm{~S}(6-7 \mathrm{~kb})$ were found. Within a year, mRNAs as part of polyribosomes had been identified as "medium-sized," 1-3 kb, DNA-like RNA (Penman et al. 1963). While it was relatively straightforward to make the case for processing of the $\mathrm{G}+\mathrm{C}$-rich $45 \mathrm{~S}$ preribosomal, likely nucleolar (Perry 1962) molecule, into the G+Crich 32S-28S and 18S ribosomal molecules (Darnell 1962; Scherrer et al. 1963), only a tantalizing suspicion existed for the possibility of large DNA-like (low $\mathrm{G}+\mathrm{C}$ ) nuclear RNA (so-called hnRNA) as the precursor to much smaller polyribosomal DNA-like (low $\mathrm{G}+\mathrm{C}$ ) presumed mRNA.

\section{PolyA-first strong indication of pre-mRNA processing}

In 1971-1972, a 3' unitary-sized polyA segment was discovered in polyribosomal mRNA (Darnell et al. 1971b; Edmonds et al. 1971; Lee et al. 1971). Mary Edmonds, with Richard Abrams, had discovered a polyA polymerase in lymphocyte extracts that needed no primer (Edmonds and Abrams 1960) and George Brawerman had found a polyA segment in rat liver cytoplasm (Hadjivassiliou and Brawerman 1966). However, without a look into the RNA found in polyribosomes, this unusual sequence had not found a home.

Proof that this unit of pure adenylic acid residues was added first to nuclear RNA by enzymes, as Edmonds and Abrams reported, and then the same-sized unit appeared in polyribosomal mRNAs within a few minutes, was the first strong suggestion of processing of large nuclear molecules in the formation of mRNA (Darnell et al. 1971a; Jelinek et al. 1973; Nakazato et al. 1973).

The discovery of polyA addition was followed by the discovery in 1974-1975 of the addition of the $5^{\prime}$-methylated $\mathrm{GpppX}_{\mathrm{m}} \mathrm{p}$ cap at the $5^{\prime}$ end of animal virus mRNA (Shatkin 1974; Wei and Moss 1974; Furuichi et al. 1975a). That same structure was soon found also in both cellular nuclear RNA and polyribosomal mRNA (Perry and Kelley 1974; Furuichi et al. 1975b; Wei et al. 1975; Salditt-Georgieff et al. 1976).

\section{Discovery of splicing and spliceosomes}

Finally, in the spring of 1977, electron microscopic (EM) analysis of late (18 h of infection) adenovirus mRNAs (synthesized from adenovirus DNA by host nuclear enzymes and containing both caps and polyA) (Philipson et al. 1971; Sommer et al. 1976) uncovered splicing (Berget et al. 1977a,b; Broker et al. 1977; Chow et al. 1977a,b; Chow and Broker 1978). Many different completed late cytoplasmic adenovirus mRNAs all bound to adenovirus DNA at the same three short regions close to the transcription start site and to individual, more distant downstream genomic segments. The EM photos revealed that, most likely, RNA splicing-a revolutionary idea-reduced the large $(\sim 28 \mathrm{~kb})$ adenovirus primary RNA transcripts defined by labeled nascent RNA studies (Bachenheimer and Darnell 1975; Goldberg et al. 1977; Weber et al. 1977) to smaller cytoplasmic mRNAs. Not only did these groundbreaking electron micrographs first illustrate the event of splicing, but they also revealed that one of $\sim 15$ different mRNAs emerged (one per primary transcript) from each single large adenovirus pre-mRNA (Broker et al. 1977; Chow et al. 1977a; Berget and Sharp 1978; Chow and Broker 1978), portending regulated differential splicing. Very quickly, many other animal virus RNAs, followed by individual cellular RNAs, were shown to be spliced using the EM and other molecular techniques. 
The first genomic sequence that confirmed the necessity for splicing was for the mouse $\beta$-globin gene, described in December of 1978 (Konkel et al. 1978).

In the three and a half decades that have followed the discovery of splicing, intense interest and effort have established intricate details of, first, the surprising RNA chemistry involved in splicing (transesterification mediated by RNA: RNA interactions) (summarized in Cech 1983, 2009). At about the same time came the discovery of a set of small nuclear RNAs contained in nuclear ribonucleoprotein structures —-spliceosomes (Hinterberger et al. 1983; Brody and Abelson 1985; for review, see Steitz 1987; Sharp 1991). With the aid of dozens of processing factors, spliceosomes orchestrate the site-specific transesterification reaction. By the early1990s, the spliceosome was shown to be assembled at each splice event and to act in a dynamic stepwise process that links exons in mRNAs (for review, see Wahl et al. 2009).

\section{${ }^{3} \mathrm{H}$ nucleosides and pre-mRNA synthesis in HeLa cells}

The earliest biochemical experiments that ultimately had a direct bearing on pre-mRNA processing utilized the flow of ${ }^{3} \mathrm{H}$ nucleosides (first uridine and later adenosine) into large nuclear RNA and, with a short delay, into much smaller polyribosomal RNA, reasonably assumed to be mRNA.

Label times of 10, 20, and $45 \mathrm{sec}$ with ${ }^{3} \mathrm{H}$ uridine (Derman and Darnell 1974; Derman et al. 1976) established that it was possible to label only nascent RNA in the large nonribosomal nuclear RNA (hnRNA, heterogeneous nuclear RNA) (Soeiro et al. 1966; Perry and Kelley 1970). Accumulation of label at these three short times was not linear but in the ratio of 1:4:15, indicating the nucleoside triphosphate pool was not yet at peak radioactivity even by $45 \mathrm{sec}$ (Fig. 1A). Further, the sedimentation profile of these briefly labeled growing RNA chains was virtually identical at the three times, and the labeled molecules had a maximum at $\sim 4-5 \mathrm{~kb}$ but ranged in size up to at least $40 \mathrm{~kb}$. However, after a 30 -min exposure to ${ }^{3} \mathrm{H}$ uridine, the nonribosomal nuclear RNA sedimentation profile had a maximum in molecules $>14 \mathrm{~kb}$. Thus, the molecules labeled for $45 \mathrm{sec}$ or less were growing nascent RNA chains, and all transcripts of whatever eventual size would be equally labeled only on their growing $3^{\prime}$ ends. Numerical analysis of the size of the labeled nascent RNA chains showed 50\%-60\% would eventually be larger than the 5-kb marker (28S rRNA), and $>30 \%$ of the eventually finished RNA chains would be larger than the 14-kb marker (45 pre-rRNA) (Derman et al. 1976). These conclusions gibe well with the transcript lengths now determined by whole-genome sequence analysis of DNA and by sequence of transcribed nonribosomal RNA ( $\left.\mathrm{RNA}_{\text {seq }}\right)$.

Total nuclear molecules briefly labeled with ${ }^{3} \mathrm{H}$ adenosine gave a very similar sedimentation profile to the ${ }^{3} \mathrm{H}$ uridine-labeled molecules. PolyA ${ }^{+}$nuclear RNA also became labeled in 2 min and $\sim 50 \%$ of the labeled $\sim 230$-nt polyA segment was added to molecules larger than $6.7 \mathrm{~kb}$ (32S) (Fig. 1B; Derman and Darnell 1974; Sawicki et al. 1977).
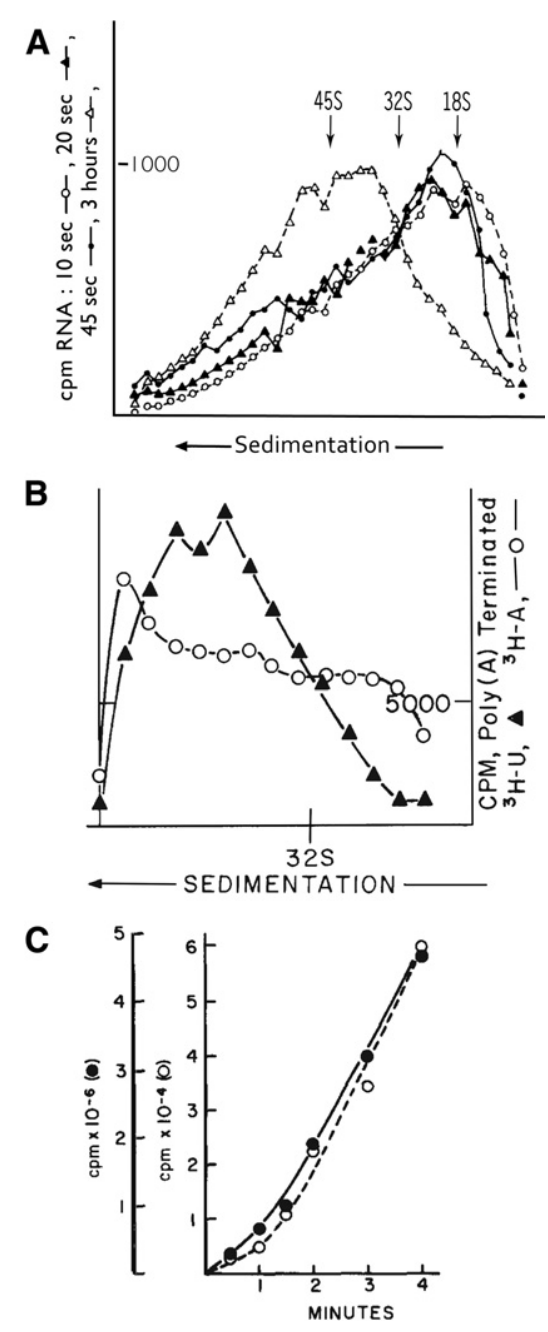

FIGURE 1. Nascent RNA in HeLa cells. (A) Growing cells were labeled

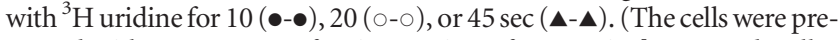
treated with $0.04 \mu \mathrm{g} / \mathrm{mL}$ of actinomycin D for $25 \mathrm{~min}$ [Perry and Kelley 1970] so that no pre-rRNA, only hnRNA, was labeled.) Nuclear RNA was extracted, treated with DMSO to assure no aggregation, and sedimented with markers ( $\Delta^{32} \mathrm{P}$ hnRNA, steady state; 3 -h label), and, in another tube, $45 \mathrm{~S}(14 \mathrm{~kb}), 32 \mathrm{~S}(6.7 \mathrm{~kb})$, and $18 \mathrm{~S}(2 \mathrm{~kb})$ preribosomal and ribosomal RNAs (from Fig. 3 in Derman et al. 1976). (B) PolyA ${ }^{+}$nuclear RNA, pulselabeled. Cells were labeled for $30 \mathrm{sec}$ with ${ }^{3} \mathrm{H}$ uridine or ${ }^{3} \mathrm{H}$ adenosine as in $A$, hnRNA was extracted and molecules larger than $5 \mathrm{~kb}(28 \mathrm{~S})$ selected and submitted to polyU sepharose binding, elution with $30 \%$ formamide (denaturing concentration), and sedimented through a second sucrose gradient to determine their size. The ${ }^{3} \mathrm{H}$ adenosine-labeled RNA was assayed both for total CPM (O-०) and for labeled polyA (data not shown in this figure); $\sim 60 \%$ of the polyA was in molecules $6.7 \mathrm{~kb}$ and larger (32S marker) and $\sim 40 \%$ was in smaller polyA ${ }^{+}$molecules (from Fig. 4 in Derman and Darnell 1974). (C) ${ }^{3} \mathrm{H}$ uridine flow into polyA ${ }^{+}$and polyA ${ }^{-}$hnRNA fragments. Cells were briefly labeled as indicated; total hnRNA was extracted, broken with brief alkali treatment to $\sim 500$-nt fragments and polyA ${ }^{+}$and polyA ${ }^{-}$fragments counted (from Fig. 2 in Salditt-Georgieff et al. 1980).

Even in steady state, $>60 \%$ of ${ }^{32} \mathrm{P}$-labeled polyA ${ }^{+}$hnRNA molecules were larger than $6.7 \mathrm{~kb}$ (32S pre-rRNA), while $80 \%$ of polyribosomal mRNA was smaller than $2 \mathrm{~kb}(18 \mathrm{~S}$ rRNA) (Derman et al. 1976; Salditt-Georgieff et al. 1976). So, if processing delivered most or all of the polyA to the 
cytoplasmic mRNA (see Puckett et al. 1975), polyadenylation generally preceded the completion of processing, whatever that entailed.

Another result pertinent to the timing of polyA addition was the flow of ${ }^{3} \mathrm{H}$ uridine into total hnRNA and into uridine residues next to polyA. Limited alkaline treatment of extracted nuclear nonribosomal RNA after brief label times of ${ }^{3} \mathrm{H}$ uridine incorporation ( $30 \mathrm{sec}$ to $4 \mathrm{~min}$ ) reduced all labeled molecules to an average size of $\sim 500 \mathrm{nt}$, and polyA ${ }^{+}$fragments and polyA ${ }^{-}$fragments were separated. The polyA ${ }^{-} \sim 500-\mathrm{nt}$ hnRNA fragments and the polyA ${ }^{+}$fragments accumulated label at almost the same rate, with labeling of polyA+ fragments lagging by, at most, $30 \mathrm{sec}$ (Salditt-Georgieff et al. 1980). PolyA addition, therefore, occurred within, at most, $30 \mathrm{sec}$ to newly synthesized nuclear RNA (Fig. 1C).

Altogether, these early experiments provided very strong evidence (prior to the discovery of splicing) that much of the polyA was quickly added in the nucleus to molecules much larger than mRNA and that, beginning 5-10 min later, the same 230-nt 3' polyA unit (Jelinek et al. 1973; Sawicki et al. 1977; Salditt-Georgieff et al. 1980) began to accumulate in increasing amounts in the much smaller cytoplasmic polyribosomal mRNA. As we shall see, the early short-label experiments are consonant with the latest RNA $_{\text {seq }}$ studies on nascent, still chromatin-associated molecules (Bhatt et al. 2012; A Pandya-Jones, DM Bhatt, C-H Lin, ST Smale, and DL Black, in prep.)

\section{Brief labeling of specific nuclear RNAs}

The experiments discussed above were carried out on total RNA samples. A few early studies were also performed with briefly labeled, specific pre-mRNA transcripts from both viral and cellular DNA. Globin precursor to mRNA (Kinniburgh and Ross 1979) and immunoglobin nuclear RNA precursors to heavy chain $(11 \mathrm{~kb})$ and light chain (3.3 and $5.3 \mathrm{~kb}$ ) mRNAs (Schibler et al. 1978) became labeled and polyadenylated more prominently than labeled mRNA-sized molecules. The same was true for briefly labeled SV40 (Lai et al. 1978) and early adenovirus (Weber et al. 1980) primary transcripts and mRNA molecules. Obviously, polyA was added to all these relatively short precursor molecules before they were spliced.

Detailed examination of the kinetics of the major late adenovirus transcription unit and the molecules produced and Darnell 1978b). from it also was greatly illuminating. For example, cleavage and polyA addition occurred within $45 \mathrm{sec}$ of RNA polymerase passage of a chosen polyA site (Berget and Sharp 1978; Nevins and Darnell 1978a,b; LeMoullec et al. 1983). The briefly labeled, polyA-terminated, nuclear adenovirusspecific pre-mRNA appeared to stretch from (at least near) the transcription initiation site to one of the possible polyA sites (Fig. 2). These molecules had been cleaved and polyadenylated within seconds at one (and only one) of the five polyA ${ }^{+}$sites used to process the primary transcript but had not yet been shortened to mRNA size by the splicing events that would produce one of the $\sim 15$ much shorter mRNAs. Evidence was strong that each primary transcription event, nevertheless, continued to a position $\sim 28 \mathrm{~kb}$ from the initiation site, stopping at an apparent single transcription termination site or region near to, but not at, the end of the linear genome (Fraser et al. 1979).

However, it was soon convincingly shown with labeled late nuclear adenovirus transcripts that the major late transcript did, in fact, begin to be spliced at its $5^{\prime}$ end (Keohavong et al. 1982; Mariman et al. 1983) before transcription was complete. All the late adeno mRNAs contain three noncoding "leader" sequences: L1, L2, and L3 (Berget et al. 1977a,b;

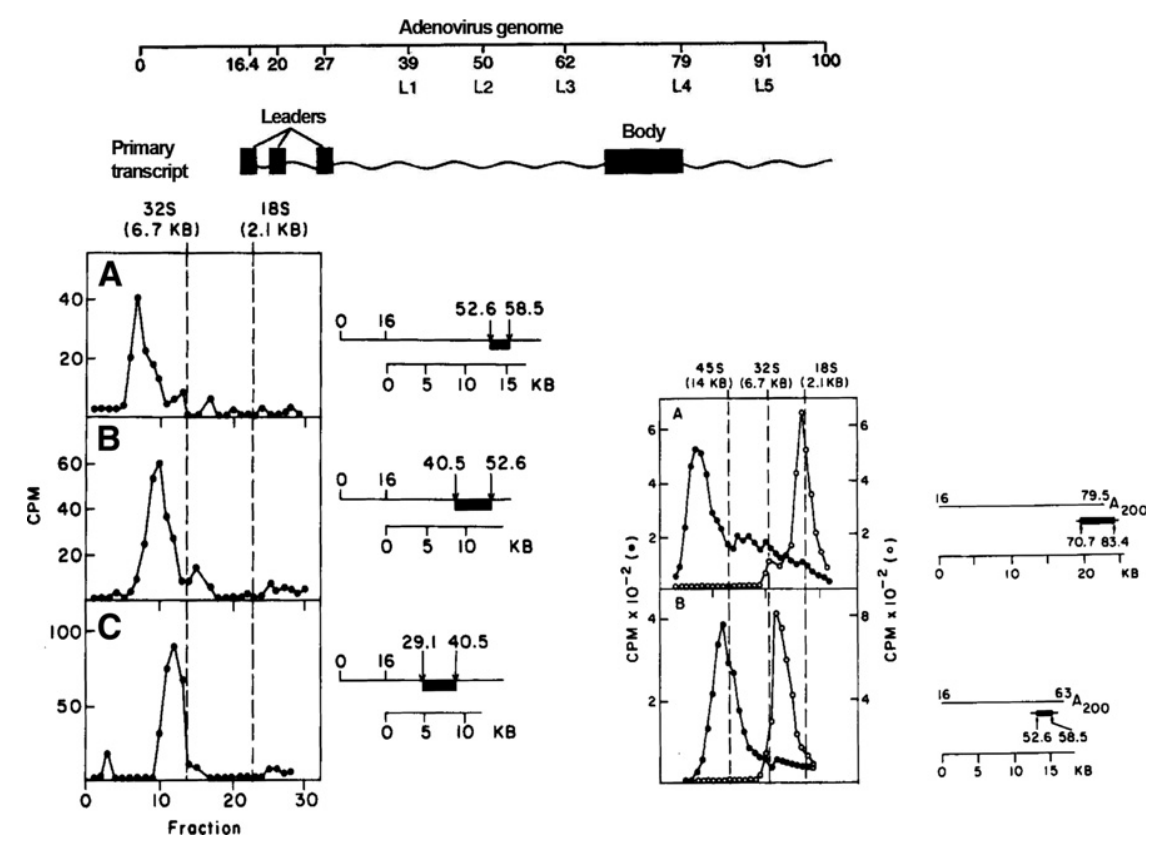

FIGURE 2. Addition of polyA during transcription of late adenovirus 2 pre-mRNA. Diagram at top shows adenovirus genome $(0-100,1$ unit $=360$ bases $)$. mRNA products have three leader sequences found in all late mRNAs. Primary transcript begins at $\sim 16.4$ and map positions for five sites of polyA addition are indicated ( $\mathrm{L} 1,2,3,4$, and 5). Spliced example shown includes a coding sequence (body) with polyA at L4 site. Graphs below show two experiments (A, B, C on left; A, B on right with cells $18 \mathrm{~h}$ after adenovirus infection). ${ }^{3} \mathrm{H}$ uridine-labeled nuclear RNA (45 sec) was separated by sucrose gradient sedimentation. Fractions were assayed for RNAse-resistant hybridization to indicated adenovirus DNA fragments $(\bullet-\bullet)$ from selected regions of the genome (on right of each graph). Size markers of rRNA $\left(45,32\right.$, or $18 \mathrm{~S}$ markers located by $\mathrm{OD}_{260}$ ) were added as size markers (horizontal dashed lines). In experiment on the right, adenovirus cytoplasmic mRNA labeled for $15-18 \mathrm{~h}$ with ${ }^{32} \mathrm{P}$ served as an additional size maker (०-०) (Fig. 2 in Nevins 
Broker et al. 1977; Chow and Broker 1978). L1 is 50 nt long and contains the $5^{\prime}$ cap structure; L2 is $\sim 80 \mathrm{nt}$ long and maps $\sim 1100$ nt downstream from L1; L3 is $~ 100$ nt long and maps $\sim 2500$ nt downstream from L2. The L1to L2 splice occurs within seconds to minutes after transcription, but the L1-L2 splice to L3 requires over $10 \mathrm{~min}$ to occur, and additional time is required for final splicing to a downstream messenger RNA "body" that encodes protein (Fig. 3; Keohavong et al. 1982; Mariman et al. 1983). From these results, it was clear that some splices take longer than others and some can occur prior to completion of an entire pre-mRNA, a theme that has carried forward ever since.

\section{EARLY EM OBSERVATIONS OF UNIDENTIFIED BUT SPECIFIC NASCENT RNAS}

Direct observation by electron microscopy of nonribosomal RNAPII nascent transcripts was achieved in O. L. Miller's group (Miller and Beatty 1969) using the technique of gentle detergent lysis of cells. The first report revealed the famous "Christmas tree" arrays of pre-rRNA on nucleolar genes demonstrating the simultaneous transcription by multiple sequentially initiated RNAP I molecules. The procedure then was used on cells from early Drosophila embryos (Beyer et al. 1981) to examine nonribosomal transcripts. Although the specificity of sequences being transcribed was unknown, Beyer and Osheim, nevertheless, could study multiple nascent RNA molecules arising from individual transcription units
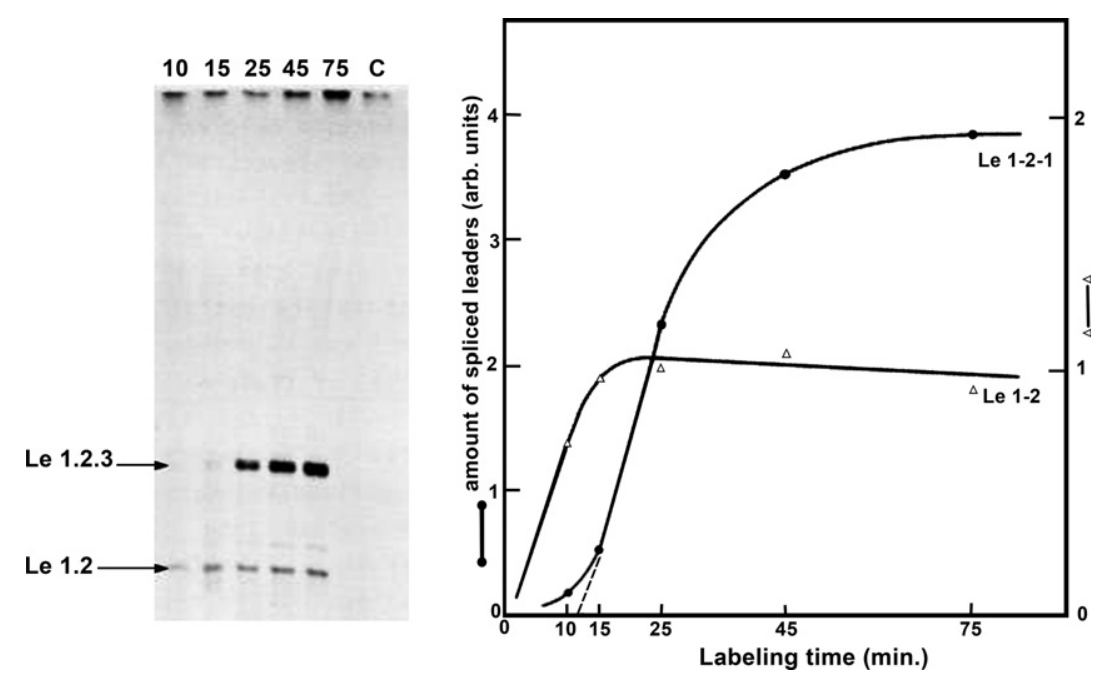

FIGURE 3. Time course of splicing adenovirus mRNA leader sequences. Adenovirus 2-infected $\mathrm{HeLa}$ cells at $16 \mathrm{~h}$ after infection were labeled with ${ }^{3} \mathrm{H}$ uridine for indicated times (10 to 75 min), and total cell RNA was isolated. DNA containing all three spliced leader sequences was cloned from cDNA copies of late Ad-2 mRNA. Hybridization of labeled mRNA from each time sample to the DNA segment containing the three leader sequences was followed by RNAse treatment and proteolytic enzyme digestion to purify the DNA-RNA hybrid. RNADNA hybrids were recovered and immediately separated by electrophoresis. (Left) One example of gel electrophoresis and autoradiogram of hybridized Ad-2 RNAs from cells labeled for indicated times. (Right) Graph is plot of labeled, hybridized RNA as a function of time. Leader 1-2 linkage was rapid $\left(T_{1 / 2}<1-2 \mathrm{~min}\right.$ ), and L1-L2-L3 linkage lagged by $\sim 15 \mathrm{~min}$ (in Figs. 3, 4 in Keohavong et al. 1982). presumably undergoing transcription by RNAPII (Beyer and Osheim 1988).

Some individual nascent RNA primary transcripts still associated with RNAPII on the same template DNA had "small particles" at two sites upstream on individual growing RNA molecules. These "small particles" were positioned at the same downstream distance from the $5^{\prime}$ end of the growing RNA on different individual transcripts from the same chromosomal locus (Fig. 4). In addition, on some transcripts where the polymerase had progressed farther downstream, there were loops in between the sites occupied on other transcripts by "small particles" that now had larger particles at the base of the loop. Finally, cases were observed even farther downstream where the loops had been removed, resulting in a shortened nascent RNA still associated with the chromoome, and the polymerase was farther downstream.

The quite reasonable interpretation of these elegant experiments was that the particles were spliceosomes, the massive structures we now know are responsible for splicing, in the process of forming and that processing (splicing) could begin uring transcription and, in some cases, could be completed (loops removed) before release of the primary transcript. estimated the time required between these measured intial events-small particles more $5^{\prime}$, then larger partiremova by the distance moved on the DNA template tween the first small particle deposition and loop removal. Using the number of 1.5 to $2 \mathrm{~kb}$ per min for the estimated RNAPII elongation rate in Drosophila cells at $25^{\circ} \mathrm{C}$, as had been published for other insect larvae (Egyhazi 1974; Lai et al. 1978), loop removal (completion of splicing) took $\sim 3$ min to occur.

In addition to the demonstration that splicing appears to occur on some nascent transcripts before transcription is completed, two most important points in Beyer's early experiments are often not emphasized. First, the time for completion of presumed splicing was $3 \mathrm{~min}$, and the polymerase had moved downstream far beyond the presumed splice site by this time. Second, the frequency of observed splicing on individual transcripts from a variety of different nascent RNAs was low ( $40 \%-50 \%$ of transcripts at most), so the majority of splicing on long transcripts in these cells apparently was performed after the RNA polymerase had transcribed the region and left the splice site.

Another early experiment (not using EM) also showed some splicing could occur on nascent Drosophila premRNA (Lemaire and Thummel 1990). 

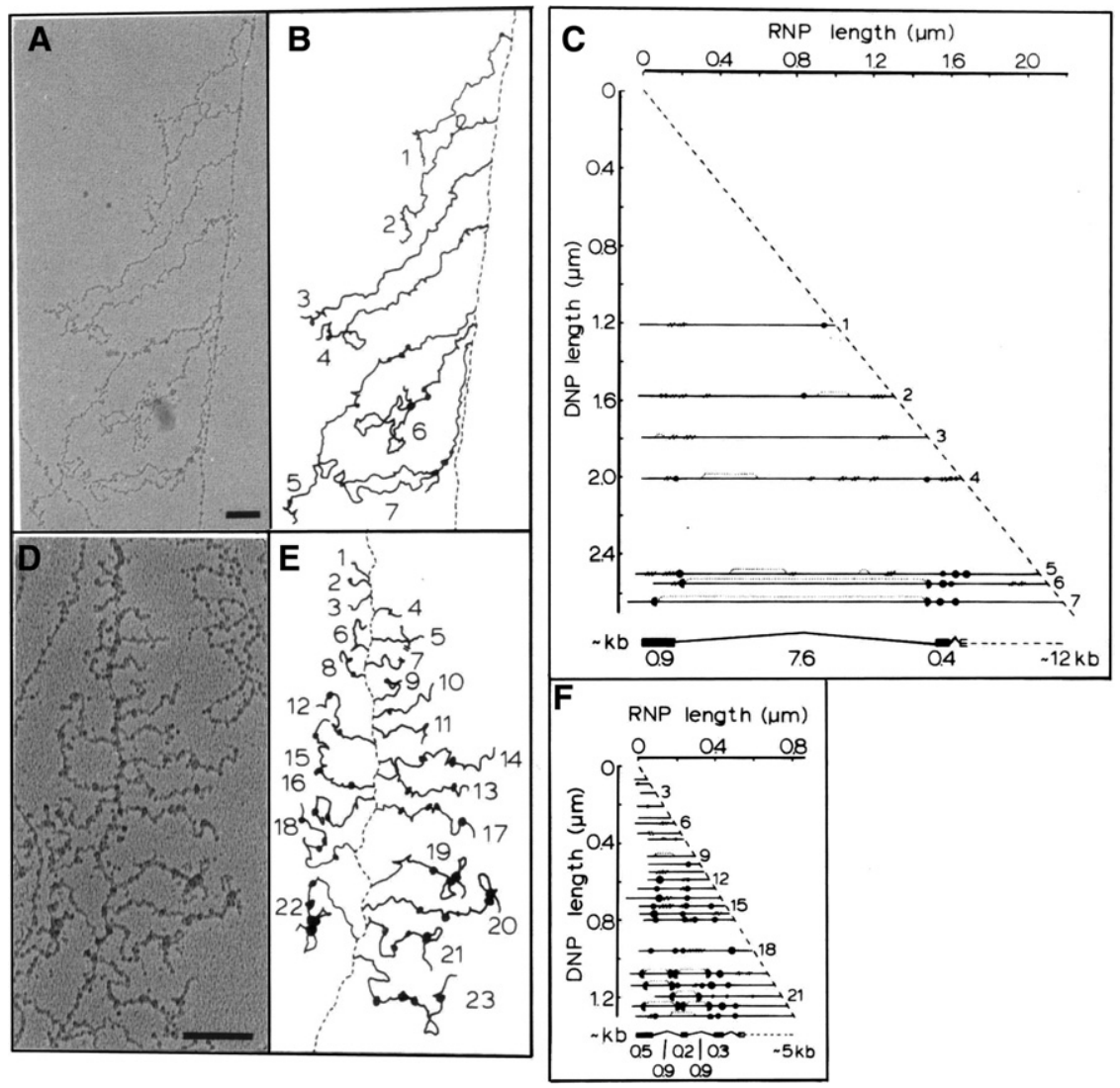

FIGURE 4. Electron micrographs of Drosophila pre-mRNA synthesis and partial processing during transcription. Detergent-spread Drosophila embryonic cells were examined; two different pre$\mathrm{mRNAs}$ are shown $(A, D)$. Tracings in $B$ and $E$ show diagram of RNP fibrils deriving from transcription of each gene and the position of small and large presumed RNAP particles bound to the nascent RNA which survive the detergent treatment required to prepare the spreads. Graphs at right $(C, F)$ represent summaries of the position of large and small particles on pre-mRNA fibrils that provide an estimate of intron length and elapsed time for processing (see text; Fig. 2 in Beyer and Osheim 1988). sumed to be united more slowly at a later time since they were spliced in finished mRNA (Lemaire and Thummel 1990).

\section{EARLY LINKAGE TO PRE-MRNA PROCESSING OF RNAPII}

Growing in parallel to information on processing during the 1980s was an ever-increasing depth of knowledge of the details of transcription. RNA polymerase II, the enzyme discovered in 1969 (Roeder and Rutter 1969), that produces primary transcripts, including all pre-mRNAs, requires the assistance of, perhaps, hundreds of proteins to initiate and complete regulated pre-mRNA production (for review, see Thomas and Chiang 2006; Malik and Roeder 2010; Buratowski 2012). Integration between RNA synthesis and processing has become a central topic of research in the last 15-20 yr. Particularly important in this integration has been the role of the repeated heptads and their regulated phosphorylation in the carboxyl terminal domain (CTD) of the largest RNAPII subunit. This remarkable and unusual structure was discovered in 1985 (Allison et al. 1985; Corden et al. 1985; for review, see Phatnani and Greenleaf 2006; JP Hsin and JL Manley, in prep.).

By now dozens of CTD binding pro-

The ecdysone-inducible E74A mRNA is a 6-kb mRNA containing eight exons derived from a $60-\mathrm{kb}$ transcript that was estimated to require perhaps 30-60 min to transcribe completely, as no complete mRNA was detected for this long after induction. Splicing was scored over the first five exons contained in the first $12 \mathrm{~kb}$ of the nascent pre-mRNA. This was measured by protection against RNAse of labeled antisense probe RNA transcribed from cloned exons including extensions at each end of the exons, hybridized to extracted nuclear RNA, followed by nuclease digestion and sizing of the protected probe. By 15 min after ecdysone treatment, presumably before transcription could be finished, exon borders were evident (i.e., cleavage at their $5^{\prime}$ borders had occurred), and some exon joining could be detected. Curiously, the intron between exons 1 and 2 and between exons 2 and 3 had not been removed, whereas at least the introns between exons 3 and 4 and 4 and 5 had all been cleaved out and the exons united by this time. So while splicing occurred to some exons before the primary transcript was completed, the polymerase had passed exons 1 and 2 which were pre- teins are well-documented, some of which act in capping pre-mRNA, some in splicing or polyA formation (for review, see Shuman 2002; JP Hsin and JL Manley, in prep.). More recently, dozens more proteins have been recognized that act in promoting chain synthesis through "chromatin" (nucleosome covered DNA), some of which can also bind the CTD (Workman 2006).

\section{Rate of RNAPII chain elongation}

Knowing the speed of RNA chain elongation by RNAPII is crucial to the consideration of the timing and order of processing events and the nature and extent of the integration with transcription of transcriptionally important proteins (RNAPII and associated proteins) and processing factors.

The anti-viral compound DRB (5,6-dichloro-1- $\beta$-D-ribofuranosylbenzimidazole), which prevents chain elongation beyond promoter proximal pause sites by inhibiting the PTEFb kinase (Core and Lis 2008; Core et al. 2008), has been extremely useful in determining chain elongation rate. 
For example, using DRB, Endre Egyhazi in 1974 (Egyhazi 1974) reported that the already started giant, $75 S$ mRNA, encoding a secreted protein in the salivary gland of Chironomus tentans, continued to be elongated at $\sim 30 \mathrm{nt}$ per sec $(\sim 2 \mathrm{~kb} / \mathrm{min})$ at $25^{\circ}$, the temperature at which these larvae thrive.

The previously described older studies on labeled nascent RNA in cultured mammalian cells (Derman and Darnell 1974) afforded a chance using DRB to estimate chain elongation rate in mammalian cells. Already initiated hnRNA chains greater than a few hundred nucleotides continued to be labeled with ${ }^{3} \mathrm{H}$ uridine in HeLa cells in the presence of DRB at an estimated $\sim 50 \mathrm{nt}$ per sec ( $3 \mathrm{~kb}$ per min), slightly faster than the estimated rate in C. tentans (Sehgal et al. 1976, 1979).

Recently, Singh and Padgett (2009) used DRB to empty RNAPII from actively transcribed genes in cultured human cells. Upon removal of the drug, they extracted the nuclear RNA and scored transcriptional rates during resumption of transcription. The synthesis rate in pre-mRNA was scored by RT-PCR amplification of known sequences within many different very long primary transcripts. These extremely clear experiments showed a 3-4 $\mathrm{kb}$ per min rate of elongation throughout the primary transcripts, including very long introns (see Fig. 5). However, most important for later discussion, the transcription rate through long regions densely packed with exons also occurred at the same high rate. Multiple $5^{\prime}$ exon-intron and $3^{\prime}$ intron-exon junctions did not measurably impede the rate of RNAPII elongation (details discussed later) (see Fig. 5).

Singer and colleagues (Darzacq et al. 2007) installed in human cells specifically constructed, tandemly arranged genes, the inducible transcriptional product of which contained RNA sequences that bound a fluorescent protein probe so that the time required for transcription at the inserted site could be charted. They obtained a maximum rate of $4.3 \mathrm{~kb}$ per min, with some irregularity in polymerase movement at different sites of integration. A second report (Brody et al. 2011) using a very similar approach measured RNA polymerase elongation rate at $3.6 \mathrm{~kb}$ per min.

An additional straightforward biochemical technique recently measured chain elongation rate in cultured human cells (Wada et al. 2009) by following the synthesis of specific nascent pre-mRNA induced by the cytokine TNF $\alpha$. The primary transcript elongation rate was measured in short intervals (min) by hybridization of induced nascent RNA to a tiling array of DNA. In addition, this group also used a fluorescent assay. A growth rate of $3.1 \mathrm{~kb}$ per min was obtained with both techniques (see Fig. 5C).

Satisfyingly, estimations of the synthetic rate of RNAPII in mammalian cells have been constant for 35 years; it is $3-4 \mathrm{~kb}$ per min. Thus, a 10-kb pre-mRNA transcript, for example, requires $3 \mathrm{~min}$ or less for complete synthesis. These time considerations are very relevant to the order of splicing and of polyA addition. The most direct measurement of RNAPII elongation rate in vivo in yeast, charted by the time of the ac- cumulation of RNAPII on the $3^{\prime}$ ends of induced genes, was estimated to be $\sim 2 \mathrm{~kb} / \mathrm{min}$ (Mason and Struhl 2005). Thus, in all these cases, the elongation rate was estimated to be $\sim 30-50 \mathrm{nt} / \mathrm{sec}$, with all of the mammalian estimates falling in the faster range.

A recent review has professed doubt about whether these "average" elongation rates adequately allow for some "irregularity" in transcription rate (e.g., purposeful pausing at splice sites) (Oesterreich et al. 2011). We will return to this important unsolved question later.

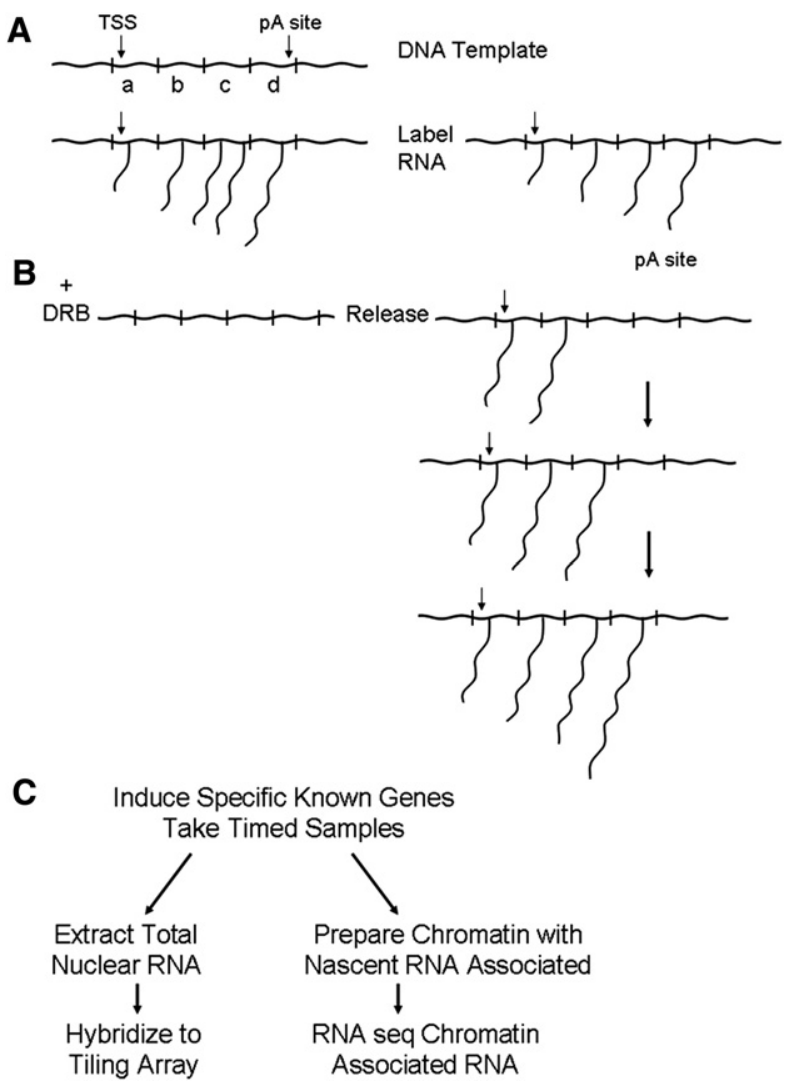

FIGURE 5. Using nascent RNA to study pre-mRNA synthesis and processing. (A) Short pulse-label times with ${ }^{3} \mathrm{H}$ uridine ( $\sim 1$ min or less) revealed nascent RNA profile (see Fig. 1A). (TSS) transcription short site, (pA) polyA site. Hybridization of such labeled RNA to segments of a known DNA (a, b, c, d) template were used to map individual transcription units that prove fast polyA addition time (see Figs. 1C, 2) and demonstrate the first recognized cotranscriptional splicing (see Fig. 3). (B) Experimental discharge of nascent RNA with DRB treatment followed by removal allows nascent RNA synthesis to resume from at (or very near) the transcription start site. Given total genome sequencing, progress of transcription across any selected gene can be monitored by choosing primers at various sites and RT-PCR amplifying nascent, newly started RNA. This allows a measurement of elapsed time to transcribe across a gene and with selected primers in both exons and introns to determine extent of cotranscriptional splicing (see Pandya-Jones and Black 2009; Singh and Padgett 2009; Wada et al. 2009). (C) Studying nascent RNA from individual inducible genes. Nascent RNA has been studied on induced genes recently hybridized to tiling arrays of DNA (see Wada et al. 2011) and by $\mathrm{RNA}_{\text {seq }}$ in several labs after preparing chromatin-associated RNA (see Bhatt et al. 2012; A Pandya-Jones, DM Bhatt, C-H Lin, A-J Tong, ST Smale, and DL Black, in prep.). 


\section{RECENT EXPERIMENTS EXPLORING INTEGRATION OF TRANSCRIPTION AND SPLICING: 'COTRANSCRIPTIONAL SPLICING'}

Two types of recent information are reviewed: (1) examination with modern techniques of studying nascent chains still associated with chromatin to determine when and where splicing and polyA processing events occur; and (2) the role of the RNA pol II CTD in possibly directly delivering splicing and polyadenylation factors to processing sites during or very shortly after transcription. While a great deal of the processing machinery, like the transcriptional machinery, is represented in both mammalian cells and yeast cells, much of the interest especially in regulated processing is focused on mammalian cells. Most of what is discussed deals with reports about animal cell (mammalian) RNA processing.

What is at issue, as we shall see, is not the possibility, indeed, the likelihood, that proteins associated with RNAPII transcription complexes assist in choosing the several sequences required in each splice but whether it is likely that there is an obligatory role and a pause by RNAPII around every splicing sequence, as suggested by some authors (Oesterreich et al. 2010, 2011; de la Mata et al. 2011).

\section{Locating nascent RNA within the nucleus}

Once proteins involved in splicing were identified, antibodies to these factors were promptly developed. Experiments in mammalian cells using fluorescent antibodies found processing proteins clustered in many punctate sites ("speckles") scattered throughout the nucleus, as well as weaker staining on chromosomes. However, the speckles are not loci of processing (e.g., Huang and Spector 1991; for review, see Maniatis and Reed 2002). It seems quite likely the speckles are "storage bins" and not sites of pre-mRNA splicing. In experiments mentioned earlier in the section discussing chain elongation rates, Singer and colleagues (Darzacq et al. 2007) used constructed genes containing DNA sequences that, when inducibly transcribed, can be detected with the use of fluorescent proteins that bind the specific nascent RNA to act as a cytologic reporter. Similar reports (Brody et al. 2011) make clear that transcription and processing of the marked pre-mRNA transcripts occurs at (or very near) the chromosomal site of integrated genes. The nascent RNA and the integrated DNA can be separately detected by hybridization using differently marked fluorescent RNA and DNA probes. The two nucleic acid probes are in the same locale although the integration of the introduced and transcribed genes occurs at multiple sites. This transcription and beginning processing are not coincident with antibody-detected "processing protein clusters." In view of the occurrence of frequent splicing before transcription is complete (discussed below), these experiments argue strongly that the bulk of splicing and polyadenylation appears to occur on nascent RNAs near the chromosomal site of synthesis.

\section{Following selected nascent RNA from early transcription: Splicing of nascent RNA and time required}

In experiments mentioned earlier on chain elongation rate, Singh and Padgett (2009) also provided some of the clearest evidence that splicing does occur on a variety of nascent, not yet completed pre-mRNAs in human cells. These experiments (see Fig. 5B) utilized DRB to empty genes of RNAPII transcripts, followed by removing the drug to allow transcription to resume. PCR primers that could detect unspliced exon-intron and intron-exon junctions, as well as primers to detect exon-exon unions, were used to score splicing at various times after DRB removal in multiple sites along the primary transcript. The unambiguous results showed frequent exon-exon union did occur to not yet fully transcribed molecules, with a higher frequency but not exclusively toward the $5^{\prime}$ end of the primary transcript, long before the RNAPII could possibly have reached all the way to the polyA site in these very long transcription units. However, even in these extremely long pre-mRNAs, only part of the necessary splicing had occurred in the $3^{\prime}$ half of the nascent pre-mRNA.

Singh and Padgett were also able to measure the time required for a splice to be completed as the RNAPII extended these nascent RNAs. Once again, the measured RNAPII rate of elongation of $\sim 3-4 \mathrm{~kb}$ per min allowed a measure of the time elapsed after an RNAPII complex passed both the $5^{\prime}$ exon-intron junction and the $3^{\prime}$ intron-exon junction before exon-exon union. The time for splicing after passage across to the $3^{\prime}$ intron-exon junction was $\sim 5$ min for nine sites and $10 \mathrm{~min}$ for five other splice sites. (Also see Audibert et al. [2002], using a very different approach based on time for completion of an mRNA compared to time of synthesis.)

These results argue against long pausing of RNAPII at every splice site (hinted at by Oesterreich et al. 2011). In two thoroughly analyzed genes, Singh and Padgett detected no difference in chain elongation rate of nascent RNA from one gene of an intron of $110 \mathrm{~kb}$ (no splices) compared to a region of $133 \mathrm{~kb}$ with five exons. In other genes, the elongation rate of $3-4 \mathrm{~kb} / \mathrm{min}$ was the same in two regions of $174 \mathrm{~kb}$ with $49 \mathrm{ex}-$ ons and another 105-kb region with 35 exons. In the case of these two primary transcripts, if there were a pause of, say, 1 min at each $5^{\prime}$ exon-intron junction and $2 \mathrm{~min}$ at each branch point/polypyrimidine stretch that marks the $3^{\prime}$ intron-exon junction, it would triple the time observed for RNAPII to transcribe these regions at $3 \mathrm{~kb} / \mathrm{min}$. If the pause were only, say, $\sim 10 \mathrm{sec}$, the Singh and Padgett experiments might not have detected such minor interruptions. So, it seems clear from the outset of the consideration of integration of splicing and transcription (see Figs. 3, 4) that "cotranscriptional" splicing cannot mean that the RNAPII complex only leaves a newly transcribed intron after it has been removed, but brief pausing at specific sites seems possible and very much needs to be settled (see later discussion). 
Also, in yeast that generally have only short transcripts that are spliced at single sites, only partial splicing during transcription is the rule. Using a high-throughput sequencing analysis of splicing in 239 yeast pre-mRNAs, Tardiff et al. (2006) searched for completion during transcription of these transcripts. A great many yeast genes with introns encode ribosomal proteins, and the pre-mRNA for these is relatively short, $<3 \mathrm{~kb}$. Tardiff and colleagues detected four times as much polyA ${ }^{+}$unspliced RNA as spliced mRNA from genes with one or two short exons, reminiscent of the early nucleoside labeling experiments with globin, immunoglobin, and animal virus transcripts described in an earlier section. Furthermore, analysis of total pre-mRNA processing by determining binding (ChIP) of spliceosomal components (U1 snRNPs and U2, 4,5 snRNPs) showed that the great majority of yeast pre-mRNAs did not have time during synthesis to assemble a complete spliceosome and to finish splicing during synthesis. Thus invariant, completed cotranscriptional splicing seemed not to be the rule, although cotranscriptional splicing in yeast can certainly occur in genes with longer $3^{\prime}$ exons.

While extrapolations about times of complex interactions in vitro to in vivo actuality are unwarranted, it is noteworthy that a recent study measuring the time required to assemble individual yeast spliceosomes in vitro was at least 10-15 min (Hoskins et al. 2011).

\section{Recent studies on nascent RNA in mammalian cells and in Drosophila}

Perhaps the most convincing and informative approach to studying the mechanics of pre-mRNA processing involves nuclear fractionation (using $0.3 \mathrm{M} \mathrm{NaCl}$ and $1 \mathrm{M}$ urea), leaving chromatin (at least, nucleosomes) intact with the great majority of nascent pre-mRNA still associated. This technique (Wuarin and Schibler 1994) was originally used with radioactively labeled DNA probes and showed that the nascent transcripts of two genes in the mouse liver nuclei underwent some but not complete splicing while the transcript was still attached to the DNA in chromatin.

With the availability of complete genome sequences, nascent RNA in chromatin prepared by this technique was examined for splicing using sequence specific approaches by Amy Pandya-Jones and Douglas Black (Pandya-Jones and Black 2009). Their initial experiments concentrated on two long transcription units in cultured human cells, cellular $s r c$ (csrc) and fibronectin, the genes for both of which are actively transcribed and are over $50 \mathrm{~kb}$ long with multiple introns. Pandya-Jones and Black adopted the strategy of using pairs of primers that span $5^{\prime}$ exon-intron and $3^{\prime}$ intron-exon junctions as well as primer pairs spanning neighboring exons in mRNA. Use of the two sets of primers accurately detected unspliced primary transcripts as well as the union of two neighboring exons. About 50\% of introns were removed from the nascent transcripts and was mainly (not completely) orderly from $5^{\prime}$ to $3^{\prime}$. Moreover, several of the exons in the two pre-mRNAs were known to be alternatively spliced, and this regulated splicing was also detected on the nascent pre-mRNA but, again, was not totally complete (see Fig. 5B).

These experiments were important for another reason. Both chromatin-associated nascent RNA and any nuclear RNA that did not fractionate with chromatin were examined. There was a great deal more pre-mRNA detected that was bound to chromatin than in the unbound nuclear RNA faction. Very little incompletely spliced pre-mRNA was released from the chromatin. Furthermore, the experiments implied completed mRNA must be transported rapidly compared to the synthesis and processing time of pre-mRNA.

In another recent contribution to the "efficiency of splicing" literature on chromatin-associated nascent RNA, Rosbash and colleagues (Khodor et al. 2011) reported on Drosophila S2 cultured cells and on total fly "head" RNA (using the technique of Wuarin and Schibler [1994] to prepare chromatin). In a very exhaustive analysis with high-throughput total RNA sequencing (RNA-seq), they found many introns were spliced in this nascent RNA at $\sim 80 \%$ efficiency. But, to quote, "1689 genes had 2793 introns with $>50 \%$ cotranscriptional intron retention."

Among the most recent experiments on nascent premRNAs are the collaborative efforts in the laboratories of Douglas Black and Stephen Smale (Bhatt et al. 2012; A Pandya-Jones, DM Bhatt, C-H Lin, ST Smale, and DL Black, in prep.). They describe the RNA-seq examination of the chromosomally associated nascent pre-mRNAs that add considerably to the proof of retention on chromatin of not yet completely spliced pre-mRNAs, most likely even after polyA addition. In addition, the experiments suggest that transcriptionally complete but not completely spliced transcripts remain associated until processing is completed.

A distinct advantage of these latest experiments is that the authors stimulated the otherwise untreated cells under study (macrophages) with lipid A, an agent that induces the inflammatory response and the prompt induced increase of transcription in macrophage-like cells of many known genes, followed by a transcriptional decrease. The experiments reported on three classes of RNA: nascent chromosomal RNA, nucleoplasmic RNA (the nuclear RNA that did not sediment with chromatin), and cytoplasmic polyA+ RNA. The $\mathrm{RNA}_{\text {seq }}$ technique affords a quantitative assessment of the amount of transcribed nascent RNA ("RNA reads") across the entire length of an induced gene. Thus, exon and intron content of pre-mRNA associated with any given gene was measured. Genes that exhibited at least a fivefold induction of chromatin-bound RNA (nascent RNA) were examined after $15,30,60$, and $120 \mathrm{~min}$. which afforded examination throughout a rise and fall of transcription reflected by a large increase and then a decrease in chromatin-associated nascent RNA for individual genes. There was a time delay in the appearance of any RNA in the nucleoplasm and a slightly longer time for an increase in the polyA-containing cytoplasmic fraction. An important point was re-emphasized-much more 
induced RNA existed on the chromatin than in the nucleoplasm from all of these acutely induced genes.

Many points pertinent to a consideration of processing were further illuminated by the details of the experiments. Virtually all of the induced nascent RNAs showed some splicing, but at least half of the final splices were not completed (especially those near the $3^{\prime}$ end of the transcript) by the time the full-length nascent RNA had reached the polyA site. An abrupt, steep fall-off of transcripts— "reads" - (not to zero) occurred at the polyA site of these pre-mRNAs, although it is firmly established that RNAPII most often continues transcription beyond the polyA site (see Fraser et al. 1978; Hofer and Darnell 1981 for old evidence examining pulse-labeled RNA). Recent experiments (for review, see Richard and Manley 2009) indicate that "torpedo" destruction of post-polyA site cleaved transcripts by a $5^{\prime}$ to $3^{\prime}$ exonuclease following closely behind RNAPII might not leave much evidence that these regions are, in fact, transcribed.

The results from the Black and Smale labs clearly indicate that the chromosomal pre-mRNA contained nonspliced transcripts, and most likely, some are already cleaved at polyA sites. The chromatin-associated transcripts were not proven to be polyadenylated, but reflecting on the old results showing, at most, $30 \mathrm{sec}$ is necessary for polyA addition (Derman and Darnell 1974; Salditt-Georgieff et al. 1980), it seems likely that at least some of this incompletely spliced RNA has already been polyadenylated and is "waiting" both to complete splicing and to associate with exon junction complexes (Tange et al. 2004) or transport proteins (Stewart 2007) needed to safely enter the cytoplasm. Whether the unspliced sites are random or represent particularly "difficult" or "slow" splice junctions is not yet clear. In contrast, virtually all of the molecules in the nucleoplasm were completely spliced and polyadenylated, as were those in the cytoplasm.

A final note on the frequency of cotranscriptional removal of introns (and the attitude of authors toward their data) comes from high-throughput sequencing of nascent RNA. The impressive international effort of the ENCODE project in which presumed nascent RNA (not prepared by the Wuarin and Schibler technique) was subjected to "deep sequencing" and reported to be $>50 \%$ and thus "predominantly cotranscriptional" (Tilgner et al. 2012). The Rosbash lab, using the Wuarin-Schibler technique, compared total Drosophila head and cell culture nascent RNA and mouse liver nascent RNA for splicing during transcription (Khodor et al. 2012). As noted earlier, $\sim 75 \%$ of total Drosophila nascent RNA was spliced, but only $45 \%$ of mouse liver nascent RNA was spliced (Khodor et al. 2011).

The reasonable conclusion from all of these extensive recent reports plus older work is that "cotranscriptional" splicing occurs, but for at least $50 \%$ of mammalian genes, and probably for all relative short ( $<10 \mathrm{~kb}$ or less?) genes, polymerization is complete and polyA addition has occurred before splicing is complete. The two major processing events are not obligatorily connected mechanistically.

\section{PRE-MRNA PROCESSING PROTEINS AND INTEGRATION WITH TRANSCRIPTION}

All of the foregoing discussion has dealt with the existence and timing of processing steps and location within the nucleus of the site of synthesis of nascent RNA. In the past $25 \mathrm{yr}$, biochemistry and genome sequencing have succeeded in identifying many dozens of RNA binding proteins, protein complexes, and enzymes that function in RNA processing and, in many cases, have uncovered details of their function. This vast area of research is quite beyond extensive coverage in this review but has been well served by numerous reviews on processing in general as well as differential and cell-specific processing (Bentley 2002, 2005; Maniatis and Reed 2002; Maniatis and Tasic 2002; Black 2003; Watson 2006; Licatalosi et al. 2008; Chen and Manley 2009; Richard and Manley 2009; Wahl et al. 2009; Licatalosi and Darnell 2010; Nilsen and Graveley 2010; Zhang et al. 2010; Oesterreich et al. 2011). In the past 10-15 yr, a major question arose on which we do wish to focus. How and when do these proteins (and complexes) become integrated into the transcription and processing system?

In this connection, several instances have been described where, in addition to specific transcription activators (Nogues et al. 2002; Tasic et al. 2002; for review, see Kornblihtt 2005) and coactivators (Auboeuf et al. 2005), processing proteins are found by ChIP analysis at specific promoter sites. In these cases, proteins such as splicing factor 1 (Fu 1995) that assists in snRNP1 recognition of the $5^{\prime}$ exon-intron junction presumably join the activation complex at the start site and accompany the RNAPII complex. The factors appear then to promote splicing at favored splice sites.

\section{Focus on the CTD}

Strong evidence began building in the 1990s, with close to a consensus belief at present, that the $-\mathrm{COOH}$ terminal domain, the CTD, of the largest subunit of RNAPII plays a necessary and decisive role in ensuring efficiency of processing, with the inherent implication that proteins (complexes) are deposited on growing RNAs very quickly after the nascent RNA has emerged from the RNAPII exit channel.

The CTD consists of heptad repeats $\left(\mathrm{Y}_{1} \mathrm{~S}_{2} \mathrm{P}_{3} \mathrm{~T}_{4} \mathrm{~S}_{5} \mathrm{P}_{6} \mathrm{~S}_{7} ; 52\right.$ in mammals and 26 in yeast) in which all three serines (S) 2, 5, and 7 , threonine $\left(\mathrm{T}_{4}\right)$, and tyrosine $\left(\mathrm{Y}_{1}\right)$ are subject to phosphorylation at different stages of transcription, providing changing affinities for different processing factors (for review, see Buratowski 2009; Munoz et al. 2010; Hsin and Manley 2012). Moreover, it is proven that various proteins important in elongating and processing the pre-mRNA can bind to the phosphorylated CTD (for review, see Reed 2003; Gornemann et al. 2005; Listerman et al. 2006; Core and Lis 2008; Chen and Manley 2009; Richard and Manley 2009; Hsin and Manley 2012). These proteins include factors implicated in capping the pre-mRNA, splice site recognition, 
and splicing execution (e.g., SR proteins and polypyrimidine binding proteins, CDK kinases and phosphatases). Particularly well-studied are several different proteins involved in polyA cleavage and polyA addition. More recently, individual proteins and complexes capable of modifying chromatin (methylases, acetylases, etc.) have also been found capable of binding the CTD.

Meinhart et al. (2005) provide an excellent review of the physical structure of proteins bound to the CTD segments and discuss the probable dimensions of the CTD domain. No structure of the entire CTD domain is available, but they describe several known structures with phosphorylated heptad repeats. Crystal structures show binding domains of processing proteins encompassing 1,2 , or 3 phosphorylated heptad repeats. These findings suggest that as many as $8-10$ proteins in yeast and twice that many in mammalian cells might bind simultaneously to a properly phosphorylated longitudinally structured CTD, not to mention additional associated factors not directly bound to the CTD. Moreover, the structure of the yeast RNAPII shows the CTD to be poised just at the exit channel of the whole enzyme. However, even with this enormous concentrating power of the CTD in bringing RNA processing proteins near to nascent RNA, it should be noted that there are many more different factors (e.g., $>15$ SR proteins alone) than CTD binding sites, and the stoichiometry of bound factors at any instant during transcription is unknown.

\section{The demonstrated importance of the CTD in vivo}

Experiments in David Bentley's lab using cells containing a transiently transfected $\alpha$-amanitin-resistant RNAPII were important to establish the in vivo function of the CTD. The resistant polymerase containing the CTD produced pre-mRNA that was efficiently spliced and polyadenylated (McCracken et al. 1997). In transfectants of the $\alpha$-amanitin-resistant RNAPII lacking the CTD, pre-mRNA transcripts were made equally in the presence of $\alpha$-amanitin, but neither spliced nor polyadenylated at nearly the same efficiency as in cells with the CTD (McCracken et al. 1997). However, some splicing and polyA addition of a reporter gene did occur. It seems inarguable that the CTD, properly phosphorylated, increased the efficiency of pro-cessing.

\section{Does CTD function at every processing site?}

A major issue remains-does the RNAPII-CTD-factor complex actually deliver at least one required factor at or just after transcription of every sequence element of every single splice site $\left(5^{\prime}\right.$ exon-intron, branch point/polypyrimidine region, and $3^{\prime}$ intron-exon junction) before transcription continues, or does the CTD promote efficiency of the overall process by raising the concentration of factors around nascent RNA? It is, of course, also possible that a flexible nascent chain (for some limited distance) could loop back to the CTD to pick up required factors.
It is relevant to point out that unspliced pre-mRNA can be spliced and polyadenylated in cell-free in vitro transcription systems (Lazarev and Manley 2007), thus splicing does not obligatorily require nascent RNA in the process of being synthesized. Furthermore, unspliced pre-mRNA can be injected into the nucleus of frog eggs (Bird et al. 2004) and become spliced. However, both of these situations are by no means $100 \%$ efficient and omit the fact that the added pre-mRNA is not produced from histone-associated DNA chromatin. Furthermore, coupled in vitro splicing and polyadenylation proceed more efficiently if the RNAPII CTD is functional (Hirose and Manley 1998; Hirose et al. 1999; Yu et al. 2010).

Some insight into the efficiency with which factors are delivered to nascent RNA comes from experiments with RNAPII that is mutated in the largest subunit. The effect in vitro of this mutation is to slow the transcription elongation rate on naked DNA by a factor of two. This mutation was first found in Drosophila (Coulter and Greenleaf 1985) and introduced into yeast (Howe et al. 2003). This slow mutant, also equipped with an $\alpha$-amanitin-resistance mutation, was introduced into human cells. In the presence of $\alpha$-amanitin, splicing constructs showed an increase in exon inclusion in mRNA that otherwise did not always occur (de la Mata et al. 2003; Howe et al. 2003). These results are often quoted to suggest that slower than average transcription rates (e.g., by pausing) at particular genomic sites might have a physiologic role to play in the outcome of processing.

\section{'Commitment' of pre-mRNA to processing}

One quite reasonable suggestion is that some event(s) does occur to the newly formed pre-mRNA and "commits" premRNA to splicing (for description and review, see Roberts et al. 1998; Hsin and Manley 2012). Such a CTD-induced commitment would explain all the evidence without requiring a physical hand-off of every required protein from the CTD at every splice site.

A logical candidate for a "commitment" step to splicing might be prompt recognition of the first splice element (the $5^{\prime}$ exon-intron junction) with attendant attraction of U1 snRNP. ChIP experiments from the Adrian Krainer and Robin Reed labs (Das et al. 2007) examined the total set of proteins associated with precipitated RNAPII by an antibody against the CTD. There was a higher number of associated SR proteins, the large family of proteins many of which recognize $5^{\prime}$ exon-intron junctions, than most other factors (although many others were present at lower levels in such ChIP experiments). Significantly, proteins associated with U1snRNP, but not U2snRNP, were present. However, the following question arises. There are, for example, at least a dozen different SR proteins (Fu 1995), and some are favored at particular 5' splice sites (Chen and Manley 2009; Licatalosi and Darnell 2010). How does the CTD of a given polymerase become equipped with the required $5^{\prime}$ exon-intron recognition factor? 


\section{FINISHING THE JOB: TERMINAL EXONS, POLYA CHOICES, AND TRANSCRIPTIONAL TERMINATION}

In addition to the role of the RNAPII CTD in splicing efficiency, there is also strong evidence that the single polyA addition for each pre-mRNA depends on a direct contribution of CTD-bound proteins in mammalian cells. There are four separately identified protein complexes associated with RNAPII, presumably all through the CTD. First, specific factors recognize sequences (AAUAAA and GU-rich short elements) that are the initiating signal for polyA addition. In addition, other complexes of factors that stimulate and then cleave the pre-mRNA, freeing the $3^{\prime}$ end to which polyA is added by the polyA polymerase, also can associate with the CTD. Representatives of all of these functions are demonstrated by ChIP analysis or in vitro biochemistry or both (Richard and Manley 2009; Di Giammartino et al. 2011) to interact more effectively with RNAPII through CTD contact.

The final structure that accomplishes polyA addition may include as many as 85 proteins (Shi et al. 2009), many of which are thought to have a moderating function in choosing polyA sites, perhaps by association with other processing proteins including splicing factors. If every addition of polyA involves this entire complex, such a huge structure surely does not accompany the transcription complex throughout the entire length of a transcription unit but must form at the site of polyA addition.

\section{Choice between alternative polyA sites}

At least $50 \%$ of primary transcription units in mammals have two or more polyA sites, and about one-quarter of these $(10 \%-15 \%$ of total pre-mRNAs) result in mRNAs with different coding capacity of their $3^{\prime}$ terminal exons, as illustrated originally in the late adenovirus transcript (Edwalds-Gilbert et al. 1997; Tian et al. 2005; Di Giammartino et al. 2011).

In addition, $\sim 40 \%$ of human genes exhibit differential choices of polyA sites within UTRs that very likely result in removing sequences to which microRNAs bind and lead to mRNA turnover. These alternative UTR sites often are "weaker" polyA sites (for review, see Mayr and Bartel 2009; Hornyik et al. 2010; Rosonina and Manley 2010; Di Giammartino et al. 2011). Of considerable interest is the common use of the alternative upstream UTR sites in cancer cells. In several cases, this choice depends on an increase in one or more of the well-identified core polyA factors (for review, see Di Giammartino et al. 2011).

Finally, an important role of suppressing unwanted intronic polyA sites was recently elaborated by experiments from the Gideon Dreyfuss group. U1snRNPs bind to many such sites, inhibiting their use and thereby preserving the use of "proper" downstream polyA sites (Berg et al. 2012).

As the number of known processing factors has greatly increased, particularly in the last decade, many molecules in- cluding those known to be important for splicing have now also been implicated in $3^{\prime}$ end processing. Several examples of differential polyA choices illustrate regulated events in $3^{\prime}$ end formation involving $3^{\prime}$ coding exons.

\section{Drosophila sex determination}

Several genes that determine sex in Drosophila produce mRNAs that are processed differently in males and females (for review, see Maniatis and Tasic 2002). The final effector gene is called double sex, and the male and female $d s x$ mRNAs have different $3^{\prime}$ exon content that employs different polyA sites. The female $d s x$ mRNA includes exons $1,2,3$, and 4 which contains the chosen polyA site. The male $d s x$ mRNA also includes exons 1,2, and 3 but skips exon 4 , uses exons 5 and 6 . Exon 6 contains the terminal coding sequences plus a polyA site. An extensive genetic and sequence analysis by Baker and colleagues (Baker and Wolfner 1988; Baker et al. 1989; Burtis and Baker 1989) found mutant sequences in exon 4 which contains a cluster of six repeated 11-mers in the mutant regions (Fig. 6A). These repeated elements were $\sim 600 \mathrm{nt}$ from the upstream $5^{\prime}$ splice site of exon 4 and about the same distance from the end of the short exon 4 and a $3^{\prime}$ UTR and polyA site. Maniatis and colleagues (Reed and Maniatis 1986; Lynch and Maniatis 1996; Hertel and Maniatis 1998; for review, see Maniatis and Tasic 2002) found that a female-specific protein, TRA, which is necessary for female development, binds to these repeats in company with another similar protein, TRA2, and a splicing factor, an SR protein, RBP1. It was concluded that the differential use of exon 4 and its included polyA site quite reasonably seemed to be a clear splicing choice, with the polyA addition at the end of exon 4 simply being automatic. However, nothing is known about the "strength" of the exon 4 polyA site compared to the exon 6 polyA site or about the relative concentration of polyA factors in male vs. female cells (see below).

\section{Calcitonin and CGRP (calcitonin gene-related polypeptide)}

Two secreted peptide hormones, calcitonin, a thyroid product, and CGRP, a brain product, are each processed from a longer protein precursor, but their mRNAs originate from the same pre-mRNA. RNA processing in the thyroid yields an mRNA including exons $1,2,3$, and 4 , the last of which encodes the calcitonin peptide sequence and has a polyA site (Fig. 6B). In the brain, the same pre-mRNA is processed into an mRNA containing exons $1,2,3,5$, and 6 . Exon 5 encodes the CGRP peptide sequence but has no poly site; exon 6 serves to provide a STOP codon for translation and a polyA site (Amara et al. 1984). Expression constructs (wild-type and exon 4 polyA site mutants) were examined in the Evans and Rosenfeld labs in thyroid-like and neuron-like cell lines, with the conclusion that the choice lay with processing proteins but not factors that direct a polyA choice, thus by implication, by splice choice proteins (Leff et al. 1987). 


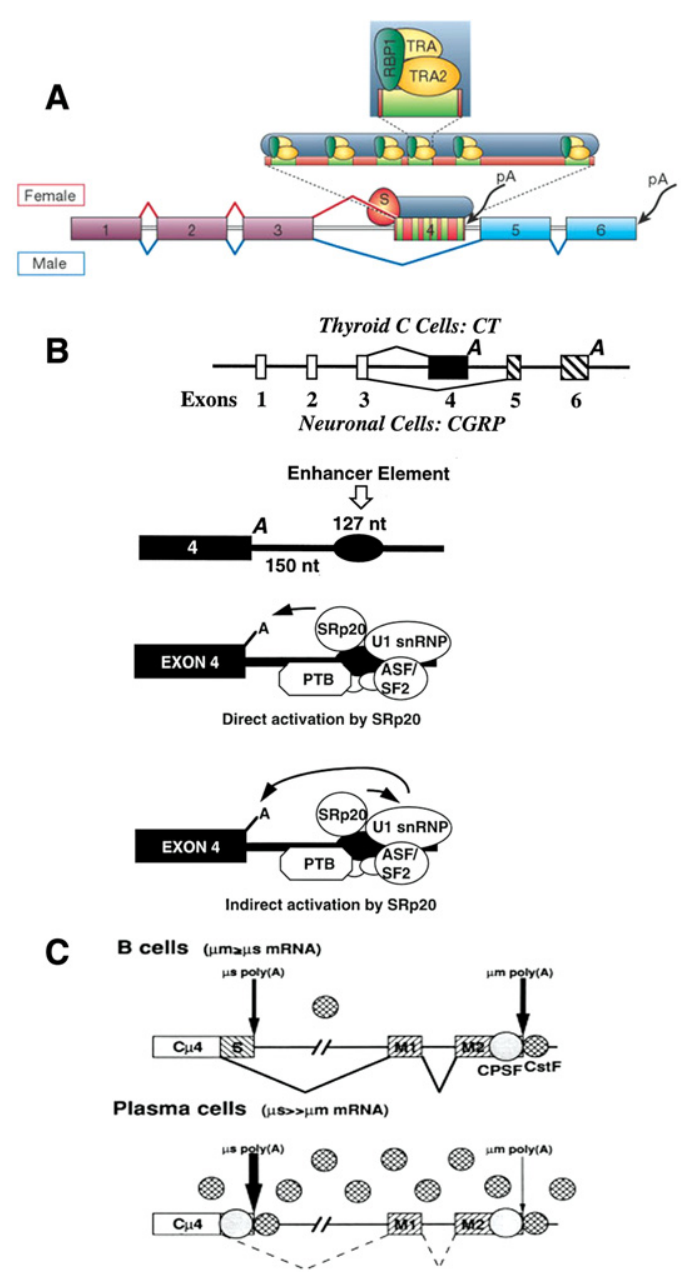

FIGURE 6. Choosing polyA sites. (A) The DSX pre-mRNA transcript is processed differently in females and males. In females, TRA proteins (SRlike proteins, yellow ellipses) are present and required to splice exon 3 to exon 4 which has a translation STOP codon and polyA site at the end of exon 4 . The identified binding sites for the TRA protein (green) and other recruited factors are a series of repeated 13-mers which are actually in exon 4. In males, the absence of TRA proteins is associated with skipping exon 4 and splicing of exon 3 to exon 5 and then to exon 6 which has a polyA site (in Fig. 2 of Maniatis and Tasic 2002). (B) (Top) Processing pre-mRNA from the gene encoding calcitonin (CT) and calcitonin gene-related protein (CGRP). The fourth exon (black) is included in the CT mRNA ending the translation of the preprotein that encodes the short CT hormone in exon 4 . In neuronal cells, exon 4 is skipped and exon 5 and exon 6 , which encodes the CGRP sequence in the pre-protein and has a functional polyA site, are included (Amara et al. 1984). (Bottom) The intron between exons 4 and 5 contains a processing enhancer element (black oval) that recruits a protein complex initiated by the binding of the SR-like protein, SRp20. This "splicing factor" has a strong affinity for CF1, a known polyA site factor. Two proposed modes of action (direct and indirect) of SRp20 for favoring exon 4 inclusion in thyroid cells are shown (in Figs. 1 and 8 in Lou et al. 1998). (C) Immunoglobulin heavy chains ( $\mu$ locus) in B cells and plasma cells. Selection of polyA sites for either the secreted form of the protein (first or $\mu$ s site) or the membrane-bound form ( $\mu \mathrm{m}$ polyA site) lead to two proteins that differ in a-COOH terminal peptide. While the pre-mRNA could be differentially spliced to include either of the-COOH terminal domains, the selection of polyA sites of the $\mu \mathrm{S}$ encoding exon is greatly favored by a large increase in CstF 64 (cross-hatched circles) in plasma cells which drives choice of the "weaker" first polyA site. The open oval (CPSF) is another required polyA factor (in Fig. 8B in Takagaki et al. 1996).
In 1998, Susan Berget's group (Lou et al. 1998) greatly illuminated the basis for the differential processing choices in the calcitonin/CGRP pre-mRNA. SRp20 is a member of the family of SR proteins that often exert effects on splice site choices by binding $5^{\prime}$ exon-intron junctions or enhancer splice sites (ESEs) within introns. Extra SRp20 cDNA expression in cells that normally excluded exon 4 (i.e., "brain-like" cells) caused production of the calcitonin-type mRNA, including exon 4 and its polyA addition site. In contrast, when mutant SRp20 protein (lacking its RS domain, the sequence that defines SR proteins, but still containing its RNA binding domain) was expressed in cells that were thyroid-like, use of exon 4 was blocked. However, the blockage was not due, at least solely, to an altered splice site choice. Srp20 does bind to an intronic sequence, but it is in the intron between exon 4 and exon 5. Srp20 also binds to cleavage factor $1(\mathrm{CF} 1)$ that is required for pre-mRNA cleavage preceding polyadenylation. CF1 has an RS domain, and it is apparently interaction between this protein and SRp20 that causes exon 4 inclusion. The decision of which downstream exon, 4 or 5 , is chosen to receive exon 3 is, therefore, not based on choosing a splice site before an exon but on the interaction of a "splicing factor" that binds after and increases the likelihood of polyadenylation at a polyA site in exon 4 upstream of the "splicing factor" (SR protein) binding site.

\section{Immunoglobulin chains: $M \mu M$ and $M \mu S$ chains}

One of the earliest studied cases of a differential use of two polyA sites resulting in two proteins of different function is the formation of two $\mu$ immunoglobulin heavy chains. The proteins are identical except for their $-\mathrm{COOH}$ terminal sequences-a 41 -aa stretch in $\mu \mathrm{M}$ that is absent from the secreted form, $\mu$ S, which ends in a different 20 aa (Fig. 6C). The 41 aa that the $\mu \mathrm{M}$ chain acquires provide a membrane-spanning domain that anchors it to the membrane (Alt et al. 1980; Early et al. 1980; Rogers et al. 1980; Galli et al. 1988). These different outcomes are brought about by use of a $3^{\prime}$ terminal exon encoding the $\sim 20$ terminal amino acids of $\mu \mathrm{S}$ plus a polyA site in this terminal exon. If this upstream polyA site is not chosen, a splice site $60 \mathrm{nt}$ upstream of a final exon encoding the membrane-spanning 41 -aa segment plus a polyA site is used.

The mature B cell produces both $\mu \mathrm{S}$ and $\mu \mathrm{M}$ about equally, whereas immunoglobulin-secreting cells, e.g., plasma cells or plasmacytoma cells, that represent the final stages of B-cell maturation produce $\mu$ s almost exclusively.

It was established that the entire region $(\sim 5 \mathrm{~kb})$ was transcribed before a choice of splice and polyA site was made. By moving elements of the gene around, thus changing the length of the intron between $\mu \mathrm{S}$ and $\mu \mathrm{M}$ exons, the Nevins and Tucker groups (Galli et al. 1987, 1988) concluded that the choice was not due to proteins in plasma cells (plasmacytoma cells) and mature B cells (lymphoma cells) that dictated splice choice because plasmids that contained only one of the two $3^{\prime}$ terminal exons and polyA sites were expressed equally. 
The choice was, instead, due to greater "strength" of the $\mu \mathrm{M}$ polyA site compared to the $\mu \mathrm{S}$ site, and if it was nearer in the pre-mRNA, it was used preferentially.

The idea of a polyA site choice was proven by Jim Manley's group in the late 1990s (Takagaki et al. 1996; Takagaki and Manley 1998). They showed that one of the necessary components, CstF-64, of the cluster of proteins that promote polyA site recognition and pre-mRNA cleavage (for review, see Richard and Manley 2009; Di Giammartino et al. 2011) is present at a much higher concentration in plasma cells than in precursor B cells. This higher concentration favors use of the "weak" upstream polyA site, allowing the $\mu$ s polyA site to be favored, which also then leads to use of the associated upstream splice site. In B cells, the "stronger" downstream site is used preferentially, as it more effectively binds the limiting amounts of CstF.

Consideration of the three cases does not provide a universal answer to how alternate $3^{\prime}$ terminal exon choices are made.

In the case of $d s x$, the evidence seems strong that a femalespecific splicing choice exists, but no information about the core group of polyA proteins is known. For the calcitonin/ CGRP there is evidence that an SR protein capable of affecting splicing also clearly can interact with and increase the activity of a core polyA factor. In the case of the $\mu \mathrm{M} / \mu$ s heavy chain choice, a demonstrated regulated increase during B-cell maturation of a core polyA protein controls exon and polyA choice. Splicing choices, perhaps, depend "only" on splicing factors, but the decision of a final exon seems to require coordination between splicing factors and polyA factors.

\section{CONCLUSION}

This review has focused on events that form mRNAs from already formed or forming pre-mRNAs in eukaryotes, mostly in mammalian cells. The crucial issues of allowing RNAPII access to the transcription start site or the proteins involved in elongation of the primary transcript past "pause" sites or the problem of removing and replacing nucleosomes as transcription proceeds have not been discussed (Workman 2006; Core and Lis 2008; Core et al. 2008).

So, what are the points of consensus about mRNA formation after RNAPII transcription past the point of initiation and elongation, and what are the major remaining areas of mystery?

1. The pre-mRNA transcript in cells bears a $5^{\prime} \mathrm{pppXp}$ which is acquired through the action of several well-known enzymes within the polymerization time of as few as $20 \mathrm{nt}$ (Babich et al. 1980; Shuman 2002; Gornemann et al. 2005). In fact, even the $\sim 30$-nt transcripts halted at early pause sites are capped (Core and Lis 2008). The CTD of pol II is crucial in delivering the capping enzymes to the initiated $5^{\prime}$ end of pre-mRNA, even acting allosterically to activate the capping enzyme (for review, see Munoz et al. 2010).

2. As soon as it was recognized that mRNA biosynthesis requires processing and that differential processing was common, two somewhat simpler questions arose, to which at least fairly firm tentative answers can be given. How long does all this take and is there an order to the steps in processing? The total array of pre-mRNA transcripts ranges from perhaps $3-5 \mathrm{~kb}$ to hundreds of kilobases in animal cells. Multiple measurements using different techniques all indicate that nascent RNA is made at $3-4 \mathrm{~kb} / \mathrm{min}$ in mammals and at $\sim 2 \mathrm{~kb} / \mathrm{min}$ in insects and yeasts. Splicing can occur as the chain is elongated, but this is not universal. Since, at least in animal cells, splicing requires several minutes after synthesis of the $3^{\prime}$ intron-exon junction, polyA addition frequently occurs before splicing is complete. There is no evidence that the time for assembly of factors to execute constitutive splicing is any different from assembly of factors that facilitate differential (including cell-specific) splicing.

3. Insofar as the cellular location of processing is concerned, the general conclusion is that nascent pre-mRNAs are processed while still associated with chromosomes. Both optical techniques and nuclear fractionation that maintains nascent pre-mRNA association with chromatin provide compelling evidence of processing close to the transcription site. Isolated chromatin with the still-associated RNAPII complex, plus incomplete nascent RNA that is, at least, partially processed settle the issue: processing factories outside of chromatin-associated proteins seem unlikely.

4. Most assuredly, the repeated heptads in the CTD of RNAPII decorated with serine phosphate(s) differentially (on S5, 2, and 7, in that order, with Y1 and T4 also playing roles), as the RNAPII complex makes it way down a gene, play an indispensable role in the efficiency of producing and processing pre-mRNA. Among others, splicing proteins that recognize the sequences surrounding $5^{\prime}$ exonintron junctions and the branch point polypyrimidinerich sequence near the $3^{\prime}$ intron-exon junction can bind the CTD. Whether the CTD binding of these factors plays an obligatory delivery role or serves to increase concentrations of necessary factors near splice sites is not settled. It seems possible, even likely, that the RNAPII does not have a physical presence long enough to deliver the correct cargo at each and every step of splicing. This interpretation is supported by the fact that older studies show that the size of molecules to which polyA is added is much larger than finished mRNA and by recent studies showing only a fraction (although, at least half) of splicing has occurred in chromatin-associated nascent pre-mRNA.

5. All considerations of RNAPII pausing for sufficient time to allow the CTD to associate with and specifically deposit one or more factors wherever required raise a question that might be answered with the high-resolution sequencing 
techniques now available. Suppose the nascent RNA closest to the RNAPII (say, the most recently synthesized $\sim 500 \mathrm{nt}$, a $\sim 10$-sec excursion of RNAPII) could be isolated by antibody affinity, together with the RNAPII complex (for example, after cleavage of nascent RNA with micrococcal nuclease). If a just-synthesized splice junction always interacts immediately with splicing factors, such interactions might impede RNAPII progress just after synthesis of a splice site and be revealed by high-resolution $\mathrm{RNA}_{\text {seq }}$ of the most recently synthesized nascent RNA.

The reported pausing of transcription around/at polyA sites may well provide time for most splicing to be completed, after which finished mRNA products are finally released for export. What seems obligatory is that an EJC (exon junction complex) complex accompanies each exon-exon junction to the cytoplasm in order to avoid nonsense mediated decay (NMD) (Nagy and Maquat 1998; Tange et al. 2004; Le Hir and Andersen 2008; Rebbapragada and Lykke-Andersen 2009; Singh et al. 2012). Furthermore, export factors for nuclear-cytoplasmic transit have been identified (Stewart 2007) and quite possibly bind before chromatin release occurs.

The regulated synthesis and the processing of mRNA in eukaryotes, especially in multicellular organisms, is probably the most demanding set of reactions of any synthesis in the cell. Questions obviously remain, but the progress in recent decades toward understanding all these events has been spectacular.

\section{ACKNOWLEDGMENTS}

The author thanks Jim Manley, Doug Black, and Rick Padgett very much for discussions and advice in the preparation of this paper.

\section{REFERENCES}

Allison LA, Movie M, Shales M, Ingles CJ. 1985. Extensive homology among the largest subunits of eukaryotic and prokaryotic RNA polymerases. Cell 42: 599-610.

Alt FW, Bothwell AL, Knapp M, Siden E, Mather E, Koshland M, Baltimore D. 1980. Synthesis of secreted and membrane-bound immunoglobulin $\mu$ heavy chains is directed by mRNAs that differ at their $3^{\prime}$ ends. Cell 20: 293-301.

Amara S, Evans RM, Rosenfeld MG. 1984. Calcitonin/calcitonin gene related peptide transcription: Tissue-specific expression involves selective use of alternative polyadenylation site. Mol Cell Biol 4: 2151-2160.

Auboeuf D, Dowhan DH, Dutertre M, Martin N, Berget SM, O'Malley BW. 2005. A subset of nuclear receptor coregulators act as coupling proteins during synthesis and maturation of RNA transcripts. Mol Cell Biol 25: 5307-5316.

Audibert A, Weil D, Dautry F. 2002. In vivo kinetics of mRNA splicing and transport in mammalian cells. Mol Cell Biol 22: 6706-6718.

Babich A, Nevins JR, Darnell JE Jr. 1980. Early capping of transcripts from the adenovirus major late transcription unit. Nature 287: 246-248.

Bachenheimer S, Darnell JE. 1975. Adenovirus 2 mRNA is transcribed as part of a high molecular weight precursor RNA. Proc Natl Acad Sci 72: $4445-4449$.
Baker BS, Wolfner MF. 1988. A molecular analysis of doublesex, a bifunctional gene that controls both male and female sexual differentiation in Drosophila melanogaster. Genes Dev 2: 477-489.

Baker BS, Burtis K, Goralski T, Mattox W, Nagushi R. 1989. Molecular and genetic aspects of sex determination in Drosophila melanogaster. Genome 31: 638-645.

Bentley DL. 2002. The mRNA assembly line: Transcription and processing machines in the same factory. Curr Opin Cell Biol 14: 336-342.

Bentley DL. 2005. Rules of engagement: Co-transcriptional recruitment of pre-mRNA processing factors. Curr Opin Cell Biol 17: 251-256.

Berg MG, Singh LN, Younis I, Liu Q, Pinto AM, Kaida D, Zhang Z, Cho S, Sherrill-Mix S, Wan L, et al. 2012. U1 snRNP determines mRNA length and regulates isoform expression. Cell 150: 53-64.

Berget SM, Sharp PA. 1978. Structure of late adenovirus 2 heterogeneous nuclear RNA. J Mol Biol 129: 547-565.

Berget SM, Berk AJ, Harrison T, Sharp PA. 1977a. Spliced segments at the $5^{\prime}$ terminus of adenovirus-2 late mRNA: A role for heterogeneous nuclear RNA in mammalian cells. Cold Spring Harb Symp Quant Biol 42: 523-530.

Berget SM, Moore C, Sharp PA. 1977b. Spliced segments at the $5^{\prime}$ terminus of adenovirus 2 late mRNA. Proc Natl Acad Sci 74: 3171-3175.

Beyer AL, Osheim YN. 1988. Splice site selection, rate of splicing and alternative splicing on nascent transcripts. Genes Dev 2: 754-765.

Beyer AL, Bouton AH, Miller OL Jr. 1981. Correlation of hnRNP structure and nascent transcript cleavage. Cell 26: 155-165.

Bhatt DM, Pandya-Jones A, Tong AJ, Barozzi I, Lissner MM, Natoli G, Black DL, Smale ST. 2012. Transcript dynamics of proinflammatory genes revealed by sequence analysis of subcellular RNA fractions. Cell 150: 279-290.

Bird G, Zorio DA, Bentley DL. 2004. RNA polymerase II carboxy-terminal domain phosphorylation is required for cotranscriptional premRNA splicing and 3'-end formation. Mol Cell Biol 24: 8963-8969.

Black DL. 2003. Mechanisms in alternative pre-messenger RNA splicing. Annu Rev Biochem 72: 291-336.

Brachet J. 1941. La détection histochimique et le microdosage des acides pentosenucléiques (tissus animaux-développement embryonnaire des amphibiens). Enzymologia 10: 87-96.

Brachet J. 1955. The biological role of the pentose nucleic acids. In The nucleic acids (ed. E Chargaff, JN Davidson), Vol. 2, pp. 475-519. Academic Press, New York.

Brenner S, Jacob F, Meselson M. 1961. An unstable intermediate carrying information from genes to ribosomes for protein synthesis. Nature 190: 576-581.

Brody E, Abelson J. 1985. The "spliceosome": Yeast pre-messenger RNA associated with a $40 \mathrm{~S}$ complex in a splicing-dependent reaction. Science 228: 963-967.

Brody Y, Neufeld N, Bieberstein N, Causse SZ, Bohnlein E-M, Neugebauer KM, Darzacq X, Shav-Tal Y. 2011. The in vivo kinetics of RNA polymerase II elongation during co-transcriptional splicing. PLoS Biol 9: e1000573.

Broker TR, Chow LT, Down AR, Gelinas RE, Hassel JA, Klessig DF, Lewis JB, Roberts RJ, Zain BS. 1977. Displacement loops in adenovirus DNA-RNA hybrids. Cold Spring Harb Symp Quant Biol 42: 531-554.

Buratowski S. 2009. Progression through the RNA polymerase II CTD cycle. Mol Cell 36: 541-546.

Buratowski S. 2012. Gene expression: Transcription initiation unwrapped. Nature 483: 286-287.

Burtis KC, Baker BS. 1989. Drosophila doublesex gene controls somatic sexual differentiation by producing alternatively spliced mRNAs encoding related sex-specific polypeptides. Cell 56: 997-1010.

Cech TR. 1983. RNA splicing: Three themes with variations. Cell 34: 713-716.

Cech TR. 2009. Crawling out of the RNA world. Cell 136: 599-603.

Chen M, Manley JL. 2009. Mechanisms of alternative splicing regulation: Insights from molecular and genomics approaches. Nat Rev Mol Cell Biol 10: 741-754. 
Chow LT, Broker TR. 1978. The spliced structures of adenovirus 2 fiber message and other late mRNAs. Cell 15: 497-510.

Chow LT, Gelinas RE, Broker TR, Roberts RJ. 1977a. An amazing sequence arrangement at the $5^{\prime}$ ends of adenovirus 2 messenger RNA. Cell 12: 1-8.

Chow LT, Roberts JM, Lewis JB, Broker TR. 1977b. A map of cytoplasmic RNA transcripts from lytic adenovirus type 2, determined by electron microscopy of RNA:DNA hybrids. Cell 11: 819-836.

Corden JL, Cadena DL, Ahearn JM Jr, Dahmus ME. 1985. A unique structure at the carboxyl terminus of the largest subunit of eukaryotic RNA polymerase II. Proc Natl Acad Sci 82: 7934-7938.

Core LJ, Lis JT. 2008. Transcription regulation through promoter-proximal pausing of RNA polymerase II. Science 319: 1791-1792.

Core LJ, Waterfall JJ, Lis JT. 2008. Nascent RNA sequencing reveals widespread pausing and divergent initiation at human promoters. Science 322: 1845-1848.

Coulter DE, Greenleaf SL. 1985. A mutation in the largest subunit of RNA polymease II alters RNA chain elongation in vitro. J Biol Chem 260: 13190-13198.

Darnell JEJ. 1962. Early events in poliovirus infection. Cold Spring Harb Symp Quant Biol 27: 149-158.

Darnell JE, Philipson L, Wall R, Adesnik M. 1971a. Polyadenylic acid sequences: Role in conversion of nuclear RNA into messenger RNA. Science 174: 507-510.

Darnell JE, Wall R, Tushinski RJ. 1971b. An adenylic acid-rich sequence in messenger RNA and its possible relationship to reiterated sites in DNA. Proc Natl Acad Sci 68: 1321-1325.

Darzacq X, Shav-Tal Y, Turris Vd, Brody Y, Henoy SM, Phair RD, Singer RH. 2007. In vivo dynamics of RNA polymerase II transcription. Nat Struct Mol Biol 14: 796-806.

Das R, Yu J, Zhang Z, Gygi MP, Krainer AR, Gygi SP, Reed R. 2007. SR proteins function in coupling RNAP II transcription to pre-mRNA splicing. Mol Cell 26: 867-881.

Davern CI, Meselson M. 1960. The molecular conservation of ribonuleic acid during bacterial growth. J Mol Biol 2: 153-160.

de la Mata M, Alonso CR, Kadener S, Fededa JP, Blaustein M, Pelisch F, Cramer P, Bentley D, Kornblihtt AR. 2003. A slow RNA polymerase II affects alternative splicing in vivo. Mol Cell 12: 525-532.

de la Mata M, Munoz MJ, Allo M, Fededa JP, Schor IE, Kornblihtt AR. 2011. RNA polymerase II elongation at the crossroads of transcription and alternative splicing. Genet Res Int 2011: 309865.

Derman E, Darnell JE. 1974. Relationship of chain transcription to poly(A) addition and processing of hnRNA in HeLa cells. Cell 3: 255-264.

Derman E, Goldberg S, Darnell JEJ. 1976. hnRNA in HeLa cells: Distribution of transcript sizes estimated from nascent molecule profile. Cell 9: 465-472.

Di Giammartino DC, Nishida K, Manley JL. 2011. Mechanisms and consequences of alternative polyadenylation. Mol Cell 43: 853-866.

Early P, Rogers J, Davis M, Calame K, Bond M, Wall R, Hood L. 1980. Two mRNAs can be produced from a single immunoglobulin $\mu$ gene by alternative RNA processing pathways. Cell 20: 313-319.

Edmonds M, Abrams R. 1960. Polynucleotide biosynthesis: Formation of a sequence of adenylate units from adenosine triphosphate by an enzyme from thymus nuclei. J Biol Chem 235: 1142-1149.

Edmonds M, Vaughan MR, Nakazato H. 1971. Polyadenylic acid sequences in the heterogeneous nuclear RNA and rapidly-labeled polyribosomal RNA of HeLa cells: Possible evidence for a precursor relationship. Proc Natl Acad Sci 68: 1336-1340.

Edwalds-Gilbert G, Veraldi KL, Milcarek C. 1997. Alternative poly(A) site selection in complex transcription units: Means to an end? Nucleic Acids Res 25: 2547-2561.

Egyhazi E. 1974. A tentative initiation inhibitor of chromosomal heterogeneous RNA synthesis. J Mol Biol 84: 173-183.

Fraser NW, Sehgal PB, Darnell JE. 1978. DRB-induced termination of late adenovirus transcription. Nature 272: 590-593.

Fraser NW, Nevins JR, Ziff E, Darnell JE. 1979. The major late adenovirus type 2 transcription unit: Termination is downstream from the last poly(A) site. J Mol Biol 129: 645-656.
Fu XD. 1995. The superfamily of arginine/serine-rich splicing factors. RNA 1: 663-680.

Furuichi Y, Morgan M, Muthukrishnan S, Shatkin AJ. 1975a. Reovirus messenger RNA contains a methylated, blocked 5'-terminal structure: $\mathrm{m}^{7} \mathrm{G}\left(5^{\prime}\right) \mathrm{ppp}\left(5^{\prime}\right) \mathrm{G}^{\mathrm{m}} \mathrm{pCp}$-. Proc Natl Acad Sci 72: 362-366.

Furuichi Y, Morgan M, Shatkin AJ, Jelinek W, Georgieff MS, Darnell JE. 1975b. Methylated, blocked 5' termini in HeLa cell mRNA. Proc Natl Acad Sci 72: 1904-1908.

Galli G, Guise JW, McDevitt MA, Tucker PW, Nevins JR. 1987. Relative position and strengths of poly(A) sites as well as transcription termination are critical to membrane versus secreted $\mu$-chain expression during B-cell development. Genes Dev 1: 471-481.

Galli G, Guise J, Tucker PW, Nevins JR. 1988. Poly(A) site choice rather than splice site choice governs the regulated production of IgM heavy-chain RNA. Proc Natl Acad Sci 85: 2439-2443.

Goldberg S, Weber J, Darnell JE. 1977. The definition of a large viral transcription unit late in Ad2 infection of HeLa cells: Mapping by effects of ultraviolet irradiation. Cell 10: 617-621.

Gornemann J, Kotovic KM, Hujer K, Neugebauer KM. 2005. Cotranscriptional spliceosome assembly occurs in a stepwise fashion and requires the cap binding complex. Mol Cell 19: 53-63.

Gros F, Hiatt H, Gilbert W, Kurland CG, Risebrough RW, Watson JD. 1961. Unstable ribonucleic acid revealed by pulse labeling of Escherichia coli. Nature 190: 681-685.

Hadjivassiliou A, Brawerman G. 1966. Polyadenylic acid in the cytoplasm of rat liver. J Mol Biol 20: 1-7.

Hall BD, Doty P. 1959. The preparation and physical chemical properties of ribonucleic acid from microsomal particles. J Mol Biol 1: 111-126.

Harris H. 1959. Turnover of nuclear and cytoplasmic ribonucleic acid in two types of animal cell, with some further observations on the nucleolus. Biochem J 73: 362-369.

Harris H, LaCour LF. 1963. Site of synthesis of cytoplasmic ribonucleic acid. Nature 200: 227-229.

Hertel KJ, Maniatis T. 1998. The function of multisite splicing enhancers. Mol Cell 1: 449-455.

Hinterberger M, Pettersson I, Steitz JA. 1983. Isolation of small nuclear ribonucleoproteins containing U1, U2, U4, U5, and U6 RNAs. J Biol Chem 258: 2604-2613.

Hirose Y, Manley JL. 1998. RNA polymerase II is an essential mRNA polyadenylation factor. Nature 395: 93-96.

Hirose Y, Tacke R, Manley JL. 1999. Phosphorylated RNA polymerase II stimulates pre-mRNA splicing. Genes Dev 13: 1234-1239.

Hofer E, Darnell JE Jr. 1981. The primary transcription unit of the mouse $\beta$-major globin gene. Cell 23: 585-593.

Hornyik C, Terzi LC, Simpson GG. 2010. The Spen family protein FPA controls alternative cleavage and polyadenylation of RNA. Dev Cell 18: $202-213$.

Hoskins AA, Friedman LJ, Gallagher SS, Crawford DJ, Anderson EG, Wombacher R, Ramierez N, Cornish VW, Gelles J, Moore MJ. 2011. Ordered and dynamic assembly of single spliceosomes. Science 331: $1289-1295$.

Howe KJ, Kane CM, Ares M Jr. 2003. Perturbation of transcription elongation influences the fidelity of internal exon inclusion in Saccharomyces cerevisiae. RNA 9: 993-1006.

Hsin JP, Manley JL. 2012. The RNA polymerase II CTD coordinates transcription and RNA processing. Genes Dev 26: 2119-2137.

Huang S, Spector DL. 1991. Nascent pre-mRNA transcripts are associated with nuclear regions enriched in splicing factors. Genes Dev 5: $2288-2303$

Jelinek W, Adesnik M, Salditt M, Sheiness D, Wall R, Molloy G, Philipson L, Darnell JE. 1973. Further evidence of the nuclear origin and transfer to the cytoplasm of poly(A) sequences in mammalian cell RNA. J Mol Biol 75: 515-532.

Keohavong P, Gattoni R, LeMoullec JM, Jacob M, Stevenin J. 1982. The orderly splicing of the first three leaders of the adenovirus- 2 major late transcript. Nucleic Acids Res 10: 1215-1229.

Khodor YL, Rodriguez J, Abruzzi KC, Tang C-HA, Marr MT II, Rosbash M. 2011. Nascent-seq indicates widespread cotranscriptional pre-mRNA splicing in Drosophila. Genes Dev 25: 2502-2512. 
Khodor YL, Menet JS, Tolan M, Rosbash M. 2012. Cotranscriptional splicing efficiency differs dramatically between Drosophila and mouse. RNA 18: 2174-2186.

Kinniburgh AJ, Ross J. 1979. Processing of the mouse $\beta$-globin mRNA precusor: At least two cleavage ligation reactions are necessary to excise the larger intervening sequence. Cell 17: 915-921.

Konkel DA, Tilghman SM, Leder P. 1978. The sequence of the chromosomal mouse $\beta$-globin major gene: Homologies in capping, splicing and poly(A) sites. Cell 15: 1125-1132.

Kornblihtt AR. 2005. Promoter usage and alternative splicing. Curr Opin Cell Biol 17: 262-268.

Kurland CG. 1960. Molecular characterization of ribonucleic acid from Escherichia coli ribosomes: I. Isolation and molecular weights. J Mol Biol 2: 83-91.

Lai CJ, Dhar R, Khoury G. 1978. Mapping the spliced and unspliced late lytic SV40 RNAs. Cell 14: 971-982.

Lazarev D, Manley JL. 2007. Concurrent splicing and transcription are not sufficient to enhance splicing efficiency. RNA 13: 1546-1557.

Le Hir H, Andersen GR. 2008. Structural insights into the exon junction complex. Curr Opin Struct Biol 18: 112-119.

Lee SEY, Mendicki J, Brawerman G. 1971. A polynucleotide segment rich in adenylic acid in the rapidly-labeled polyribosomal component in mouse sarcoma 180 ascites cells. Proc Natl Acad Sci 68: 1331-1335.

Leff SE, Evans RM, Rosenfeld MG. 1987. Splice commitment dictates neuron-specific alternative RNA processing in calcitonin/CGRP gene expesssion. Cell 48: 517-524.

Lemaire MF, Thummel CS. 1990. Splicing precedes polyadenylation during Drosophila E74A transcription. Mol Cell Biol 10: 6059-6063.

LeMoullec JM, Akusjarvi G, Stalhandske P, Pettersson U, Chambraud B, Gilardi P, Nasri M, Perricaudet M. 1983. Polyadenylic acid addition sites in the adenovirus type 2 major late transcription unit. J Virol 48: $127-134$.

Licatalosi DD, Darnell RB. 2010. RNA processing and its regulation: Global insights into biological networks. Nat Rev Genet 11: 75-87.

Licatalosi DD, Mele A, Fak JJ, Kayikci M, Chi SW, Clark TA, Schweitzer AC, Blume JE, Wang X, Darnell JC, et al. 2008. HITSCLIP yields genome-wide insights into brain alternative RNA processing. Nature 456: 464-469.

Listerman I, Sapra AK, Neugebauer KM. 2006. Cotranscriptional coupling of splicing factor recruitment and precursor messenger RNA splicing in mammalian cells. Nat Struct Mol Biol 13: 815-822.

Lou H, Neugebauer KM, Gagel RF, Berget SM. 1998. Regulation of alternative polyadenylation by U1 snRNPs and SRp20. Mol Cell Biol 18: 4977-4985.

Lynch KW, Maniatis T. 1996. Assembly of specific SR protein complexes on distinct regulatory elements of the doublesex splicing enhancer. Genes Dev 10: 2089-2101.

Malik S, Roeder RG. 2010. The metazoan Mediator co-activator complex as an integrative hub for transcriptional regulation. Nat Rev Genet 11: 761-772.

Maniatis T, Reed R. 2002. An extensive network of coupling among gene expression machines. Nature 416: 499-506.

Maniatis T, Tasic B. 2002. Alternative pre-mRNA splicing and proteosome expansion in metazoans. Nature 418: 236-243.

Mariman EC, van Beek-Reinders RJ, van Venrooij WJ. 1983. Alternative splicing pathways exist in the formation of adenoviral late messenger RNAs. J Mol Biol 163: 239-256.

Mason PB, Struhl K. 2005. Distinction and relationship between elongation rate and processivity of RNA polymerase II in vivo. Mol Cell 17: 831-840.

Mayr C, Bartel DP. 2009. Widespread shortening of 3' UTRs by alternative cleavage and polyadenylation activates oncogenes in cancer cells. Cell 138: 673-684.

McCracken S, Fong N, Yankulov K, Ballantyne S, Pan G, Greenblatt J, Patterson SD, Wickens M, Bentley DL. 1997. The C-terminal domain of RNA polymerase II couples mRNA processing to transcription. Nature 385: 357-361.
Meinhart A, Kameski T, Hoeppner S, Baumli S, Cramer P. 2005. A structural perspective of CTD function. Genes Dev 19: 1401-1415.

Miller OL, Beatty BR. 1969. Visualization of nucleolar genes. Science 164: 955-957.

Munoz MM, de la Mata M, Kornblihtt AR. 2010. The carboxy terminal domain of RNA polymerase II and alternative splicing. Trends Biochem Sci 35: 497-504.

Nagy E, Maquat LE. 1998. A rule for termination-codon position within intron-containing genes: When nonsense affects RNA abundance. Trends Biochem Sci 23: 198-199.

Nakazato H, Kopp DW, Edmonds M. 1973. Localization of the polyadenylate sequences in messenger ribonucleic acid and in the heterogeneous nuclear ribonucleic acid of HeLa cells. J Biol Chem 248: $1472-1476$

Nevins JR, Darnell JE. 1978a. Groups of adenovirus type 2 mRNAs derived from a large primary transcript. J Virol 25: 811-823.

Nevins JR, Darnell JE. 1978b. Steps in the processing of Ad2 mRNA: Poly $(\mathrm{A})^{+}$nuclear sequences are conserved and poly(A) addition precedes splicing. Cell 15: 1477-1493.

Nilsen TW, Graveley BR. 2010. Expansion of the eukaryotic proteome by alternative splicing. Nature 463: 457-463.

Nogues G, Kadener S, Cramer P, Bentley D, Kornblihtt AR. 2002. Transcriptional activators differ in their abilities to control alternative splicing. J Biol Chem 277: 43110-43114.

Oesterreich FC, Preibisch S, Neugebauer KM. 2010. Global analysis of nascent RNA reveals transcriptional pausing in terminal exons. Mol Cell 40: 571-581.

Oesterreich FC, Bieberstein N, Neugebauer KM. 2011. Pause locally, splice globally. Trends Cell Biol 21: 328-335.

Pandya-Jones A, Black DL. 2009. Co-transcriptional splicing of constitutive and alternative exons. RNA 15: 1896-1908.

Penman S, Scherrer K, Becker Y, Darnell JE. 1963. Polyribosomes in normal and poliovirus infected HeLa cells and their relationship to messenger RNA. Proc Natl Acad Sci 49: 654-662.

Perry RP. 1962. The cellular sites of synthesis of ribosomal and 4S RNA. Proc Natl Acad Sci 48: 2179-2186.

Perry RP, Kelley DE. 1970. Inhibition of RNA synthesis by actinomycin D: Characteristic dose-response of different RNA species. J Cell Physiol 76: 127-139.

Perry RP, Kelley DE. 1974. Existence of methylated messenger RNA in mouse L cells. Cell 1: 37-41.

Phatnani HP, Greenleaf AL. 2006. Phosphorylation and functions of the RNA polymerase II CTD. Genes Dev 20: 2922-2936.

Philipson L, Wall R, Glickman G, Darnell JE Jr. 1971. Addition of polyadenylate sequences to virus-specific RNA during adenovirus replication. Proc Natl Acad Sci 68: 2806-2809.

Puckett L, Chambers S, Darnell JE. 1975. Short-lived messenger RNA in HeLa cells and its impact on the kinetics of accumulation of cytoplasmic polyadenylate. Proc Natl Acad Sci 72: 389-393.

Rebbapragada I, Lykke-Andersen J. 2009. Execution of nonsense-mediated mRNA decay: What defines a substrate? Curr Opin Cell Biol 21: 394-402.

Reed R. 2003. Coupling transcripiton, splicing and mRNA export. Curr Opin Cell Biol 15: 326-331.

Reed R, Maniatis T. 1986. A role for exon sequences and slice site proximity in splice site selection. Cell 46: 681-690.

Richard P, Manley JL. 2009. Transcription termination by nuclear RNA polymerases. Genes Dev 23: 1247-1269.

Roberts GC, Gooding C, Mak HY, Proudfoot NJ, Smith CW. 1998. Cotranscriptional commitment to alternative splice site selection. Nucleic Acids Res 26: 5568-5572.

Roeder RG, Rutter WJ. 1969. Multiple forms of DNA-dependent RNA polymerase in eukaryotic organisms. Nature 224: 234-237.

Rogers J, Early P, Carter C, Calame K, Bond M, Hood L, Wall R. 1980. Two mRNAs with different $3^{\prime}$ ends encode membranebound and secreted forms of immunoglobulin $\mu$ chain. Cell 20: 303-312.

Rosonina E, Manley JL. 2010. Alternative polyadenylation blooms. Dev Cell 18: $172-174$. 
Salditt-Georgieff M, Jelinek W, Darnell JE Jr, Furuichi Y, Morgan M, Shatkin A. 1976. Methyl labeling of HeLa cell HnRNA: A comparison with mRNA. Cell 7: 227-237.

Salditt-Georgieff M, Harpold M, Sawicki S, Nevins J, Darnell JE Jr. 1980. Addition of poly(A) to nuclear RNA occurs soon after RNA synthesis. J Cell Biol 86: 844-848.

Sawicki S, Jelinek W, Darnell JE. 1977. $3^{\prime}$ terminal addition to HeLa cell nuclear and cytoplasmic poly(A). J Mol Biol 113: 219-235.

Scherrer K, Darnell JE Jr. 1962. Sedimentation characteristics of rapidly labeled RNA from HeLa cells. Biochem Biophys Res Commun 7: 486-490.

Scherrer K, Latham H, Darnell JE Jr. 1963. Demonstration of an unstable RNA and precursor to ribosomal RNA in HeLa cells. Proc Natl Acad Sci 49: 240-248.

Schibler U, Marcu KB, Perry RP. 1978. The synthesis and processing of the messenger RNAs specifying heavy and light chain immunoglobulins in MPC-11 cells. Cell 15: 1495-1509.

Sehgal PG, Derman E, Molloy GR, Tamm I, Darnell JE. 1976. 5,6Dichloro-I-b-D-ribofuranosylbenzimidazole inhibits initiation of nuclear heterogeneous RNA chains in HeLa cells. Science 94: 431-433.

Sehgal PB, Fraser N, Darnell JE. 1979. Early Ad-2 transcription units: Only promoter-proximal RNA continues to be made in the presence of DRB. Virology 94: 185-191.

Sharp PA. 1991. Five easy pieces. Science 254: 663.

Shatkin AJ. 1974. Methylated messenger RNA synthesis in vitro by purified reovirus. Proc Natl Acad Sci 71: 3204-3207.

Shi Y, Giammartino DC, Taylor D, Sarkeshik A, Rice WJ, Yates JR, Frank J, Manley JL. 2009. Molecular architecture of the human pre-mRNA 3' processing complex. Mol Cell 33: 365-376.

Shuman S. 2002. What messenger RNA capping tells us about eukaryotic evolution. Nat Rev Mol Cell Biol 3: 619-625.

Singh J, Padgett RA. 2009. Rates of in situ transcription and splicing in large human genes. Nat Struct Mol Biol 16: 1128-1133.

Singh G, Kucukural A, Cenik C, Leszyk JS, Shaffer SA, Weng Z, Moore MJ. 2012. The cellular EJC interactome reveals higher-order mRNP structure and an EJC-SR protein nexus. Cell 151: 750-764.

Smellie RMS. 1955. The metabolism of the nucleic acids. In The nucleic acids (ed. E Chargaff, JN Davidson), Vol. 2, pp. 394-429. Academic Press, New York.

Soeiro R, Birnboim HC, Darnell JE. 1966. Rapidly labeled HeLa cell nuclear RNA. II. Base composition and cellular localization of a heterogeneous RNA fraction. J Mol Biol 19: 362-372.

Sommer S, Salditt-Georgieff M, Bachenheimer S, Furuichi Y, Morgan M, Shatkin A. 1976. The methylation of adenovirus-specific nuclear and cytoplasmic RNA. Nucleic Acids Res 3: 749-766.

Steitz J. 1987. RNA splicing. In Molecular biology of RNA: New perspectives (ed. M Inouye, BS Ducock), pp. 69-80. Academic Press, New York.

Stewart M. 2007. Ratcheting mRNA out of the nucleus. Mol Cell 25: 327-330.

Takagaki Y, Manley JL. 1998. Levels of polyadenylation factor CstF-64 control IgM heavy chain mRNA accumulation and other events associated with B cell differentiation. Mol Cell 2: 761-771.

Takagaki Y, Seipelt RL, Peterson ML, Manley JL. 1996. The polyadenylation factor CstF-64 regulates alternative processing of IgM heavy chain pre-mRNA during B cell differentiation. Cell 87: 941-952.

Tange TO, Nott A, Moore MJ. 2004. The ever-increasing complexities of the exon junction complex. Curr Opin Cell Biol 16: 279-284.

Tardiff DF, Lacadie SA, Rosbash M. 2006. A genome-wide analysis indicates that yeast pre-mRNA splicing is predominantly posttranscriptional. Mol Cell 24: 917-929.

Tasic B, Nabholz CE, Baldwin KK, Kim Y, Rueckert EH, Ribich SA, Cramer P, Wu Q, Axel R, Maniatis T. 2002. Promoter choice determines splice site selection in protocadherin $\alpha$ and $\gamma$ pre-RNA splicing. Mol Cell 10: 21-33.

Thomas MC, Chiang CM. 2006. The general transcription machinery and general cofactors. Crit Rev Biochem Mol Biol 41: 105-178.

Tian B, Hu J, Zhang H, Lutz CS. 2005. A large-scale analysis of mRNA polyadenylation of human and mouse genes. Nucleic Acids Res 33: 201-212.

Tilgner H, Knowles DG, Johnson R, Davis CA, Chakrabortty S, Djebali S, Curado J, Snyder M, Gingeras TR, Guigo R. 2012. Deep sequencing of subcellular RNA fractions shows splicing to be predominantly co-transcriptional in the human genome but inefficient for lncRNAs. Genome Res 22: 1616-1625.

Wada Y, Ohta Y, Xu M, Tsutsumi S, Minami T, Inoue K, Komura D, Kitakami J, Oshida N, Papantonis A, et al. 2009. A wave of nascent transcription on activated human genes. Proc Natl Acad Sci 106: 18357-18361.

Wahl MC, Will CL, Luhrmann R. 2009. The spliceosome: Design principles of a dynamic RNP machine. Cell 136: 701-718.

Watson JD. 2006. Prologue to the first edition. In The RNA world (ed. RF Gesteland et al.), 3rd ed., pp. xv-xxiii. Cold Spring Harbor Laboratory Press, Cold Spring Harbor, NY.

Weber J, Jelinek W, Darnell JE. 1977. The definition of a large viral transcription unit late in Ad2 infection of HeLa cells: Mapping of nascent RNA molecules labeled in isolated nuclei. Cell 10: 811-816.

Weber J, Blanchard J-M, Ginsberg HM, Darnell JE. 1980. Order of polyadenylic acid addition and splicing events in early adenovirus mRNA formation. J Virol 33: 286-291.

Wei C-M, Moss B. 1974. Methylation of newly synthesized viral messenger RNA by an enzyme in vaccinia virus. Proc Natl Acad Sci 71: 3014-3018.

Wei C-M, Gershowitz A, Moss B. 1975. Methylated nucleotides block 5' terminus of HeLa cell messenger RNA. Cell 4: 379-386.

Workman JL. 2006. Nucleosome displacement in transcription. Genes Dev 20: 2009-2017.

Wuarin J, Schibler U. 1994. Physical isolation of nascent RNA chains transcribed by RNA polymerase II: Evidence for co-transcriptional splicing. Mol Cell Biol 14: 7219-7225.

Yu Y, Das R, Folco EG, Reed R. 2010. A model in vitro system for cotranscriptional splicing. Nucleic Acids Res 38: 7570-7578.

Zhang C, Frias MA, Mele A, Ruggiu M, Eom T, Marney CB, Wang H, Licatalosi DD, Fak JJ, Darnell RB. 2010. Integrative modeling defines the Nova splicing-regulatory network and its combinatorial controls. Science 329: 439-443. 

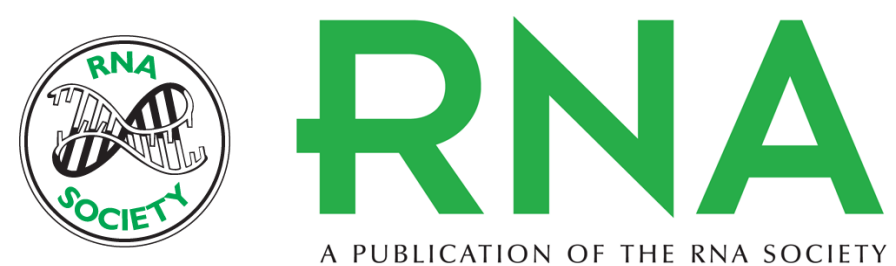

A PUBLICATION OF THE RNA SOCIETY

\section{Reflections on the history of pre-mRNA processing and highlights of current knowledge: A unified picture}

James E. Darnell, Jr.

RNA 2013 19: 443-460 originally published online February 25, 2013

Access the most recent version at doi:10.1261/rna.038596.113

$\begin{array}{ll}\text { References } & \begin{array}{l}\text { This article cites } 169 \text { articles, } 60 \text { of which can be accessed free at: } \\ \text { http://rnajournal.cshlp.org/content/19/4/443.full.html\#ref-list-1 }\end{array}\end{array}$

License

Email Alerting Receive free email alerts when new articles cite this article - sign up in the box at the Service top right corner of the article or click here. 